\title{
Adults' Self-Regulatory Behaviour Profiles in Blended Learning Environments and Their Implications for Design.
}

Stijn Van Laer \& Jan Elen

E-mail: stijn.vanlaer@ppw.kuleuven.be, jan.elen@ppw.kuleuven.be

ORCID: Stijn Van Laer (0000-0002-4825-5892), Jan Elen (0000-0003-1611-5075)

Affiliation: Centre for Instructional Psychology and Technology, KU Leuven, Dekenstraat 2, bus 3773, B-3000 Leuven, Belgium

\section{$\underline{\text { Keywords }}$}

Blended learning, Learning analytics, Self-regulation, Instructional design, Adult education

\section{$\underline{\text { Abstract }}$}

Blended forms of learning have become increasingly popular. However, it remains unclear under what circumstances blended learning environments are successful. Studies suggest that blended learning challenges learners' self-regulation. Yet little is known about what self-regulatory behaviour learners exhibit in such environments. This limited understanding is problematic since this insight is needed for effective designs. Therefore, the aim of this study was to identify learners' self-regulatory behaviour profiles in blended learning environments and to relate them to designs of blended learning environments. Learners' $(n=120)$ self-regulatory behaviour in six ecologically valid blended learning courses was captured. Log files were analysed in a learning analytics fashion for frequency, diversity, and sequence of events. Three main user profiles were identified. The designs were described using a descriptive framework containing attributes that support self-regulation in blended learning environments. Results indicate fewer mis-regulators when more self-regulatory design features are integrated. These finding highlights the value of integrating features that support selfregulation in blended learning environments. 


\section{Introduction}

Blended forms of learning have become increasingly popular (Garrison \& Kanuka, 2004; Garrison \& Vaughan, 2008; Graham, 2006; Spanjers et al., 2015). Learning activities within blended environments are supported by a large variety of online and face-to-face instructional interventions. As a result of this variety, blended learning environments (BLEs) differ widely in the technologies used, the extent of integration of online and face-to-face instruction and the degree to which online activities are meant to replace face-to-face instruction (Smith \& Kurthen, 2007). Despite their popularity, it remains unclear under what conditions these environments are successful (e.g., Oliver \& Trigwell, 2005). One important observation is that blended learning seems to be especially challenging for learners with lower self-regulatory abilities, while those with higher self-regulatory abilities seem to do well in these environments (e.g., Barnard, Lan, To, Paton, \& Lai, 2009; Lynch \& Dembo, 2004b). To date, however, it is not clear how the design of the environment affects the selfregulatory behaviour of the learner. Our limited understanding is problematic since without this information, we cannot develop evidence-based interventions and redesigns that support selfregulation and thus make learning more effective. The aim of this study was therefore to identify learners' self-regulatory behaviour profiles in BLEs and to relate these profiles to the design of the environments.

\subsection{Blended learning environments}

This study focuses exclusively on BLEs. In their editorial for the Journal of Educational Media, Whitelock and Jelfs (2003) described three definitions of the concept of blended learning. The first definition (based on Harrison (2003)) views blended learning as the integrated combination of traditional learning with web-based online approaches (Bersin \& others, 2003; Orey, 2002a, 2002b; Singh, Reed, \& others, 2001; Thomson, 2002). The second one considers it a combination of media and tools employed in an e-learning environment (Reay, 2001; Rooney, 2003; Sands, 2002; Ward \& LaBranche, 2003; Young, 2001) and the third one treats it as a combination of a number of didactic approaches, irrespective of the learning technology used (Driscoll, 2002; House, 2002; Rossett, 2002). Driscoll $(2002$, p. 1) concludes that the point is that blended learning means different things to different people, which illustrates its widely untapped potential'. Oliver and Trigwell (2005) add that the term remains unclear and ill-defined. Taking these observations into account, the definition used in this study is as follows: 'Blended learning is learning that happens in an instructional context which is characterized by a deliberate combination of online and classroom-based interventions to instigate and support learning. Learning happening in purely online or purely classroom-based instructional settings is excluded' (Boelens, Van Laer, De Wever, \& Elen, 2015).

\subsection{Self-regulation in blended learning environments}

In this study, learning is seen as an activity performed by learners in a proactive manner, rather than as something that happens to them as a result of instruction (Bandura, 1989; Benson, 2013; Knowles, Holton, \& Swanson, 2014). Learning is seen as a self-regulated process (Zimmerman \& Schunk, 2001). Various self-regulated learning theories have been founded on this perspective. Self-regulation in this study is seen as: 'The deliberate use of metacognitive skills, in a particular context, to achieve goals both internal and external to the learner.' Based on this definition, the Winne and Hadwin (1998) model was selected to reflect upon the self-regulatory behaviour of 
learners, since it has a number of characteristics that makes it very suitable for our purpose. These characteristics will be described in more detail later. Winne's Four-stage Model of Self-regulated Learning (Butler \& Winne, 1995; Winne, 1995, 1996; Winne \& Hadwin, 1998; Winne \& Perry, 2000) describes four stages: (1) task definition, during which learners develop perceptions of the task concerned, (2) goal-setting and planning, (3) enacting the tactics and strategies chosen during goalsetting and planning, and (4) metacognitively adapting studying techniques, keeping future needs in mind. Each of these phases consists of five elements (COPES): (1) conditions, which affect how a task will be engaged with, (2) operations: cognitive processes and tactics learners employs, (3) product: information created by operations, (4) evaluations: feedback about products (internal or external), and (5) standards: criteria against which products are monitored. The theory emphasizes that learners who are prompted to process effectively in stage one (task definition) and stage two (goalsetting and planning) are more likely to have accurate expectations of the task (Winne \& Hadwin, 1998). Finally each stage and its elements is influenced by certain conditions. Winne and Hadwin (1998) identify task-related conditions (e.g., time constraints, available resources and social context) and cognitive-related conditions (e.g., interest, goal orientation and task knowledge) that influence how a certain task will be engaged with (Winne \& Hadwin, 1998). Cognitive conditions are learners' epistemological beliefs, prior knowledge (all information stored in the long-term memory) and motivation (Winne \& Hadwin, 1998). In this study the focus lies on the task-related conditions, more specifically on the role of the design of BLEs. Identifying the impact of differences in BLE design makes it possible to attribute certain learners' self-regulatory behaviour to specific design features. Based on this notion more precisely targeted interventions will be possible..

The Four-stage Model of Self-regulated Learning has a number of characteristics that suit the purposes of this project very well. First, the model looks beyond the focus on purely instructional stimuli and their effects on learning, contesting the assumption that all learners process the stimuli as intended (Winne, 1982). The authors see learners as active agents (Winne, 1982, 1985, 2006) or mediating factors in the instructional process (Keller, 2010; Winne, 1982). As the learners in this project are seen as having difficulties with regulating their own learning, this scope allows us to highlight the suitability of particular designs for certain learners and to work toward 'more inclusive' environments better understood by different types of learners. A second consideration is that on the one hand, the model gives clear indications, about which phases should be targeted, namely task definition followed by goal setting and planning (Winne \& Hadwin, 1998). On the other hand, each phase (one to four) incorporates the COPES process, which makes up the cognitive system (Greene \& Azevedo, 2007). The cognitive system explicitly models how work is done in each phase and allows for a more detailed look at how various aspects of the COPES architecture interact (Greene \& Azevedo, 2007). This approach allows us to make interventions that are as targeted as possible focussing on areas that can be impacted (e.g., conditions by supporting task definition, planning and goal-setting). Third, with monitoring and control functioning as the key drivers of regulation within each phase, Winne and Hadwin's model (1998) can effectively describe how changes in one phase can lead to changes in other phases over the course of learning (Greene \& Azevedo, 2007). This allows the model to explicitly detail the recursive nature of self-regulation (Greene \& Azevedo, 2007). Fourth, the model holds a behavioural focus on self-regulation, in contrast with a focus on selfreports. This together with previous considerations aligns strongly with the focus of this project. On the one hand, because the main focus of this project lies on the support of and changes in learners' self-regulatory behaviour (by mapping their behaviour instead of asking for their perceptions). On 
the other hand, because the recursive nature of self-regulation underlines the evolving nature of it and the need of monitoring change over time. The final reason for this model's suitability is that it separates task definition, goal setting and planning into distinct phases. This allows more pertinent questions to be asked about these phases than would otherwise be possible, when focusing on instructional interventions alone (Greene \& Azevedo, 2007; Winne \& Marx, 1989).

\subsection{Adults in blended learning environments}

Research on BLEs generally praises the flexibility and suitability of such environments for adult learners (Ausburn, 2004). Adult learners are often described using the andragogy model developed by Knowles et al. (2014). In Malcolm Knowles's work, andragogy is defined more precisely as a specific theoretical and practical approach. It is based on a humanistic conception of selfdirected, autonomous learners, as well as teachers as facilitators of learning (Hansman, 2008). Others have stressed for example autonomy, self-direction, and affinity for real-life learning as key characteristics of adult learners (see e.g., Brookfield, 1986; Caffarella \& Merriam, 2000; Tough, 1978). Questions could be asked about how BLEs deal with adults that do not have these characteristics, for example second chance learners (Connolly, Murphy, \& Moore, 2007). The andragogy focuses rather on the abilities of the learner (adult in their learning and in regulating their learning). In this study we focus on learners in second-chance education. This type of education is specifically targeted at individuals who, for a variety of reasons, never attended school or left school either before completing the level of education in which they were enrolled or completed the level but wished to enter an education programme or occupation for which they were not yet qualified (UNESCO, 2011). By providing these second chances, second chance education prevents isolation from the labour market and employability (Nordlund, Bonfanti, \& Strandh, 2015). These learners have often negative prior experiences with education and dropped out of school early. When such learners enter a BLE, they may face different challenges due to their lack of self-regulation. This claim is supported by the to-date research that suggest BLEs to require a large amount of self-regulation on the part of learners (Bonk \& Graham, 2012; Collis, Bruijstens, \& van Veen, 2003). Learners need to have, when they learn in such environments, different self-regulation related skills (e.g., Lynch \& Dembo, 2004a; Sharma, Dick, Chin, \& Land, 2007). Such skills are: e.g. motivation, internet self-efficacy, time management, study environment management, and learning assistance management. Based on this claim it seems that BLEs work fine for adults with proper self-regulatory skills, but that they may fail to address the needs learners with lower self-regulatory skills (Cennamo, Ross, \& Rogers, 2002).

\subsection{Attributes that support self-regulation in blended learning environments}

As indicated above, different stages, dimensions, and processes of self-regulation may be influenced by specific instructional interventions (e.g., Bannert, 2009; Ifenthaler, 2012; Winne \& Hadwin, 1998). As pointed out by Ley and Young (2001), several self-regulation interventions have been tailored to specific content, learners, or media. Interventions have been suggested for writing (Graham, Harris, \& Troia, 1998), reading comprehension (Pressley, El-Dinary, Wharton-McDonald, \& Brown, 1998), and mathematics (Schunk, 1998). Others have incorporated support for self-regulation into college learning-to-learn courses (Hofer, Yu, \& Pintrich, 1998) or in computer-mediated instruction (Winne \& Stockley, 1998). No attempts in the literature could be found for blended learning environments. Some approaches have been directed toward specific populations such as children (Biemiller, Shany, Inglis, \& Meichenbaum, 1998; Corno, 1995), adolescents (Belfiore \& 
Hornyak, 1998), and learning disabled learners (Butler, 1998). Although there is a substantial amount of research available that describes ways to support learners' self-regulation, there are several outstanding issues that makes the practical application of these guidelines impossible. First, we were unable to find any research that addresses self-regulation as an inherent part of learning. The guidelines formulated often view self-regulation as a specific goal (to design for) instead of as an inherent attribute of learning (Schunk \& Zimmerman, 2003). Only a few studies attempted to combine findings from different backgrounds into a set of guidelines or principles for a theoretical framework. Based on this notion, Van Laer and Elen (2016) identified, using a systematic literature review ( $n=95$ ), seven attributes that support self-regulation in BLEs. The first one is authenticity, or the real-world relevance of the learning experience to learners' lives. Secondly, there is personalization, defined as the tailoring of the learning environment to the inherent preferences and needs of each individual learner. Third, learner control is the degree to which learners have control over the content and activities within the learning environment. Fourth, there is scaffolding, defined as changes in the task or learning environment, which assist learners in accomplishing tasks that would otherwise be beyond their reach. Fifth is interaction, or in what way the learning environment stimulates learners' involvement with this environment. Sixth are reflection cues, which are prompts aiming at activating learners' purposeful critical analysis of knowledge. Finally, there are calibration cues that are triggers for learners to test their perceptions against their actual performance and study tactics. The combination of these attributes configure the support system of learners' selfregulation in the learning environment. For a more detailed overview, see appendix 1 and 2.

\subsection{Measuring self-regulation}

Measurements of self-regulation have a long history in research (Veenman, Van HoutWolters, \& Afflerbach, 2006; Winne \& Perry, 2000; Zimmerman, 2008). Conceptual understanding evolved from self-regulation as an aptitude (stable character) to self-regulation as an event (turbulent character). When self-regulation is measured as an aptitude, a single measurement, aggregates over, or abstracts some quality of self-regulation. (e.g., Endedijk, Brekelmans, Sleegers, \& Vermunt, 2015; Pintrich, Smith, García, \& McKeachie, 1993; Weinstein, Zimmerman, \& Palmer, 1988). These instruments often rely on self-reports of learners. Many authors consider the results of self-reports instruments to be poor indicators of the actual regulation activities that students use while studying (Perry \& Winne, 2006; Pintrich, 2004; Veenman et al., 2006). The measurement of self-regulation as events, in contrast, is based on multiple self-regulation events (Winne \& Perry, 2000). Endedijk et al. (2015) reported on online (during the task) and offline (after the task) methods. These types of measurements appear to be more suitable for finding relations between specific aspects of real time self-regulatory behaviour in authentic contexts (Zimmerman, 2008) and have the potential to be more accurate than retrospective self-reports that require recall of actions and thoughts (Winne et al., 2006). The measurement of events in online environments is often described. Azevedo (Azevedo, Johnson, Chauncey, \& Burkett, 2010; Harley, Bouchet, Hussain, Azevedo, \& Calvo, 2015) uses MetaTutor to trace data. Winne follows a similar approach with nStudy (Winne, 2016; Winne, 2015; Winne \& Hadwin, 2013; Winne et al., 2006). Both MetaTutor and nStudy are online platforms that aim to support learners' studying. At the same time they are also able to track learners' behaviour for research purposes. Although this type of research reports on the selfregulatory behaviour of learners, it focusses solely on experimental settings and is mainly based on frequency and diversity of actions, related to performance. By applying such approach, they often lack to address the typical ecological setting of a classroom (restrictions in variables to trace, etc.) 
and the cyclic nature of self-regulation (based on the sequencing of events). During this study both frequency and diversity and the sequencing of events, based on ecological learners' log-files, will be taken into account.

\subsection{Problem statement}

Although research stresses the suitability of BLEs for adults (Brookfield, 1986; Caffarella \& Merriam, 2000; Tough, 1978), research on second chance education shows that such learners are not necessarily typical 'adult learners' (Connolly et al., 2007). Research on self-regulation in blendedlearning environments regularly reports the importance of specific self-regulatory abilities learners need, to be able to benefit from BLEs (e.g., Lynch \& Dembo, 2004b). Second chance learners often lack these abilities. Without identifying the relationships between learners' self-regulatory behaviour and the design of BLEs it is not possible to determine how design features impact learners' selfregulatory behaviour, or, consequently, to implement targeted (re)designs to overcome the problems that for example learners in second-chance education encounter. To be able to design BLEs that support self-regulation, an answer to the following research question is needed:

'What learners' self-regulatory behaviour profiles can be identified in BLEs and how do they relate to the design of these environments?'

By answering this research question, this study on the one hand presents learners' selfregulatory behaviour profiles in BLEs and on the other hand, reveals the relation between these profiles and the design of BLEs.

\section{Method}

To answer the research question, a mixed method approach was used containing three major steps. First, the learning environments were described using self-regulatory attributes of BLEs. Second, learners' self-regulatory behaviour was identified in each learning environment. Finally, a comparison between the different learning environments (and the learners' behaviour in them) was made to explore the possible relationship of the design of the learning environment on the behaviour of learners within the environment.

\subsection{Context, population and sample}

Six blended learning courses within two Flemish schools of adult education were targeted. All the courses covered the same subject, 'Introduction to basic statistics' within second chance education. Topics included were means, modes, frequency tables, etc. Each course had an identical length of eight weeks. Learners took the course in the first semester of the school year. The population was divided over the six blended learning courses $(n=120)$. All learners were aged above eighteen, had a wide diversity of prior experiences both professional and educational, some of them working already for many years, others did not have any prior experience related to work. Each of them was enrolled in the second-chance education track, as they did not have a diploma of secondary education. They had different social backgrounds and occupations, ranging from exconvicts to successful CEO's. Finally, their language levels for Dutch were sufficient (as tested at the enrolment of the program, and the distribution by sex was comparable. Both schools were similar in size and context. Due to the different architecture (database structure) of the virtual learning 
environments of both schools there will be reported on school-level. If conclusions are drawn there will be checked if they can be drawn over the two schools.

\subsection{Measurement instruments}

\subsubsection{Description of blended learning environments that support self-regulation}

To describe both the on- and off-line components of the six learning environments targeted, an observation framework was developed based on the attributes as identified by Van Laer and Elen (2016). See appendix 1 and 2 for further details. The methodology used (see: De Wever, Schellens, Valcke, \& Van Keer, 2006; Jorgensen, 1989) contains three phases (selection of content, the selection of a unit of analysis and the examination of the reliability of the instrument). For the face-to-face observations, everything the instructor said during the class was recorded, transcribed and selected for analysis. In addition, when the teacher explicitly referred to the syllabus, that specific part of the syllabus was also selected for analysis. For the observation of the online environment, we applied the same additional guideline. By choosing fixed units (Rourke, Anderson, Garrison, \& Archer, 2001), topics addressed during the course (e.g., 'Data collection', 'Data processing' and 'Statistical key concepts'), a clear unit of analysis was selected (De Wever et al., 2006). Such a topic contained a set of instructions aiming at fostering learning opportunities for learners based on a predefined set of goals. To describe the attributes observed in the learning environment, each question (see appendix 1) was answered by giving a score on a Likert-type scale (never-little-somewhat-much-always) and providing the related evidence and comments. Finally, to test this methodology, a pilot study was done. The instrument was tested using multiple raters $(n=4)$. The results from the reliability analysis showed a Kendall's W of 0.62, what according to Cicchetti (1994) is good. This indicates that the instrument developed, is reliable as far as describing the learning environment is concerned.

\subsubsection{Analysis}

Each attribute was analysed using the leading questions (Appendix 1). An Excel document was made including tabs per topic, an overview of the course and a graphical overview of the attribute per topic for the overall course. Each topic addressed was described. For each topic the presence of the attributes was investigated. When an answer on a leading question was given, a short summary of evidence for this answer was given. When all questions for a certain attribute were answered, a mean score of attributes was calculated per course. This was done for all topics within each course, and visualized. Finally, after the descriptions of each BLE were made, their scores on each Likert-type scale was gathered in a matrix (Appendix 3). Based on the matrix it became clear how the seven attributes were present in each course and how the courses compared with one another.

\subsubsection{Self-regulatory behaviour in blended learning environments}

As mentioned before, to investigate the self-regulatory behaviour of learners' in six blended learning courses, an event approach was used. The methodology was based on the ideas of Hadwin, Nesbit, Jamieson-Noel, Code, and Winne (2007) and Azevedo et al. (2010) and modified to the (ecological) needs of this study. The approach included first a traditional cluster analysis. This to determine if clusters based on self-regulatory behaviour could be identified based on the amount and diversity of interactions with the online learning environment. Using frequency is the traditional approach for analysing learners' self-regulatory behaviour (Azevedo, Cromley, Winters, Moos, \& 
Greene, 2005; Järvelä, Järvenoja, \& Malmberg, 2012; Manlove, Lazonder, \& de Jong, 2007). In contrast to previous research (see above) we did not include time-spend-per-tool, this because, in our opinion the traces gathered are rather events (clicks, contributions, etc.) then states (reading, summarizing, etc.) (Agrawal \& Srikant, 1995; Zaki, 2001). We opted to include diversity because there is evidence that this might say something about learners' regulation strategies (Azevedo, 2005). Based on this analysis, per institution learners were assigned to a specific cluster. Secondly, event sequence analysis was used to investigate learners' behaviour. The TraMineR-package (Gabadinho, Ritschard, Mueller, \& Studer, 2011) in R-statistics was used to determine if certain sequences are reported more frequently and if they are, significantly different for each cluster.

\subsubsection{Structure of online learning environments investigated}

As both schools have the same learning content management system (Moodle), they are comparable in nature. This means that both environments contain the same ecological log file data. These log files are long lists ( $+10,000$ items) of chronological events. An event is an interaction of the learner with the environment. Only log files at course level were taken into account. Although the back-end of both online learning environments was quite similar, there were some differences. School B uses a remarkable amount of SCORM-packages. These packages are learning materials that can be uploaded to the online learning environment. The use of these types of packages affects the structure of the log files. Due to this reason, it is not possible to recode and combine variables of both schools in advance and results and analyses needed to be reported per school. Although this might be a limitation regarding transparency, it is still possible to compare and generalize (over the two schools) the observations made after individual analysis. Appendix 4 shows the traced variables per school, including the significance in occurring in the different clusters.

\subsubsection{Analysis}

To identify possible clusters of self-regulatory behaviour in both schools, first cluster analysis based on diversity and frequency of events was done to deduce individual differences in learners' self-regulatory behaviour. A K-means cluster analysis was performed in R on the standardized trace variables. Outliers, defined as learners who did not interact with the environment more than ten times and did not obtain a grade for their course were excluded. To define the clusters in terms of the self-regulatory behaviour learners' represent, a MANOVA was executed. Follow-up one-way ANOVAs showed which variables report significant different values for different clusters. Secondly, cluster analysis based on the sequence of events was done using sequenced timings of events. Event sequences are the chronological listening of all events. Using the seqefsub() function of the TraMineR package (Gabadinho et al., 2011) in R, frequent event sub-sequences were looked for. While using the seqecmpgroup() function for examining differences in cluster-solutions, based on the discriminant event sequences, was used. To control the relation between self-regulatory behaviour and performance, the relation of cluster membership with performance was examined. Although the relation between self-regulation and performance is often studied (e.g., Schunk \& Zimmerman, 1994), we checked, using a MANOVA, for significant influence of the cluster membership, compared to the scores learners obtained. Finally, to answer the overall research question, on the one hand a Chi-square test of independence was administered for both schools to investigate if the environment potentially influenced the occurrence of certain clusters. On the other hand, the relation between the integration of attributes that support self-regulation (sum scores of attributes per environment) and cluster membership was uncovered by running a multinomial logistic regression. 


\section{Results}

To be able to design BLEs that support self-regulation, an answer to the following research question is needed: "What learners' self-regulatory behaviour profiles can be identified in BLEs and how do they relate to the design of these environments?". First, the design of each course (per school) will be addressed. Secondly, the self-regulatory behaviour of the learners involved (per school) will be investigated. Thirdly and finally, the relation between both the design of the learning environment and learners' self-regulatory behaviour will be examined.

\subsection{The six blended learning courses involved}

\subsubsection{Schools}

The first school (A) is situated near Hasselt. This school for adult education is one of the biggest of Flanders with over 50 course offered and over 1000 learners taking them. Four blended learning courses described where targeted in this school. Two different instructors co-designed and individually delivered two courses each. The second school is situated near Antwerp, the second biggest city of Belgium. Like the previous school, also this one is one of the biggest of Flanders with over 75 course offered and over 1500 learners taking them. Two blended learning courses were targeted. Both courses were designed and delivered by the same instructor. All six blended learning course have the same topic. The courses are numbered one to six. Below there will be elaborated on each's design, based on the seven attributes that support self-regulation.

\subsubsection{School A}

Each course in this school addressed five topics. Environment one contained two face-to-face meetings, one at the start and one on the day of the examination. During the first lesson, the instructor introduced the materials and methodology of the course. Subsequently, eight online lessons were provided. Environment two included five face-to-face lessons and five online lessons. It started and ended with a face-to-face lesson. In-between of these, every other week a face-to-face or online lesson took place. During the face-to-face lessons, the instructor mainly repeated the online lesson. Environment three was designed by the same instructor as the previous course and duplicated to another context. The only difference was that this course consisted out of three faceto-face lessons and six online lessons. Finally, environment four had seven face-to-face lessons and one online lesson (due to a holiday on a course date). For all environments each topic started with the presentation of 'Theory', including general definitions and different examples. At the end of the theoretical part, an individual research project was introduced. The theoretical part was followed by 'Exercises'; each of the exercises was framed in a different context. After the completion of the last exercise of each topic, a test followed. Only one chance was allowed.

Regarding the attributes that support self-regulation, authenticity of the different learning environments differed depending of the nature of the topic. Authenticity was observed more when the topic was in direct relation to applications of a task (for example the individual 'research' project learners had to do). Personalization in the online learning environment was primarily focused on the presentation of different contextualized exercises and on the choice learners had in selecting a topic to do their individual project on. Personalization in the face-to-face context was mostly done by addressing learners by their name or by presenting examples from learners' professional or private 
life. Further, the instructors delivered instruction mainly in a one-size-fit all approach. Learners were allowed much more learner control in the online learning environment compared to the face-to-face environments. In the online learning environments, they were free to select the sequence of topics; all topics were often visible from the first lesson onwards. Nonetheless, learners did not have control over what activity to do in which topic. The instructors defined these. In the face-to-face context, learners were allowed to take control over additional exercises when others were still working on previous ones. Scaffolding throughout the duration of the course was done by shifting responsibility towards the learner. A lot of support was provided when learners solved exercises, the individual project received the least support. In the face-to-face context, instructors tailored support to the learners' capabilities by giving personal (verbal) feedback. In the online learning environments, instructors did not tailor support to the learners. The difference in interaction between the face-toface and online contexts was remarkable. In the online learning environment, interaction focused on learner-content and learner-interface interaction. In the face-to-face context, interaction was more focussed on learner-instructor and learner-peer interaction. Finally, both cues for reflection and for calibration were addressed the least in every environment described. Reflection cues for one's own learning were not provided, neither before, during nor after one's actions. If reflection cues were given, they entailed hypothetical mistakes learners could make while solving a specific exercise. Finally, some feedback was provided on specific content elements. In both cases, no action was expected from the learners. In figure 1, the results for each of the courses (environments) can be found.

$$
\ll<\text { FIGURE } 1 \text { >> }
$$

\subsubsection{School B}

Environment five was structured in seven weekly meetings. The course consisted of three consecutive topics 'Data collection', 'Data collection', and 'Statistical key concepts'. Five of the weekly meetings were in a face-to-face format during which both the instructor and learners used online materials. Environment six started with a face-to-face session, during which the instructor introduced the individual research project, the learning materials, and the methodology of the course and gave a brief overview of the entire course. Following this session, seven online lessons were provided.

Likewise in school A, authenticity of the learning environment differed depending on the nature of the topic. Personalization was focused on the use of learners' names and only in the faceto-face context. Instruction was mainly delivered in a one-size-fit all approach. In the face-to-face context learners did not have any control over pace, content and learning activities. This contrasted very much with the situation in the online environment in which learners had ultimate freedom. Scaffolding throughout the duration of the course was done based on tailored support for the learners. Neither fading of support nor a transition of responsibility toward the learner could be observed. As in the other courses, interaction was often observed. Nonetheless, collaboration between peers was only minimally observed. Finally, cues for reflection and for calibration were addressed the least, compared to the other attributes described. Figure 2 shows the observations for these courses.

$\ll<$ FIGURE 2 >>

\subsection{Learners self-regulatory behaviour in blended learning environments}




\subsubsection{School A}

Based on, on the one hand the cluster analysis using frequency and diversity and on the other hand, patterns and discriminating sequences, the behaviour traced via ecological data was investigated. In School A ( $n=76)$ three clusters were identified. Using a MANOVA significant differences between the traced variables (independent) clusters (dependent) were found $F(72,76)=$ $5.12, p<.001$; Wilk's $\Lambda=0.029$, partial $\eta^{2}=.83$. One-way ANOVAs showed that twenty of the traced variables have significantly different values for learners in different clusters (see figure 3 and appendix 4). The analysis indicated that the amount of interaction learners had with (1) information such as the course home page (course viewed) $(F(2,73)=9.564, p=.000)$ and topic pages (course module viewed) $(F(2,73)=10.325, p=.000)$; (2) on the one hand engagement in discussions (discussion made) $(F(2,73)=9.904, p=.000)$ and on the other hand viewing them (discussion viewed) $(F(2,73)=9.243, p=.000)$; (3) formal submissions of tasks (test made) $(F(2,73)=36.914, p=$ .000 ) and assignments (assignment submitted) $(F(2,73)=27.110, p=.000)$; and finally (4) consultation of scores (user score) $(F(2,73)=33.565, p=.000)$ and results (submission form consulted) $(F(2,73)=17.934, p=.000)$ have a different appearance between clusters. Forty-one learners belonged to Cluster 1, twenty-two to Cluster 2 and thirteen to Cluster 3.

The event sequence analysis (Associated Pearson Residual of the Chi-square test, residuals $\leq-$ 2 less frequent and $\geq 2$ more frequent) showed that learners in Cluster 1 used sequences like '(course module viewed) - (discussion made)' $(r=1.50, p<.001)$ much more frequent than their counterparts from Cluster $2(r=-0.53, p<.001)$ and three $(r=-1.98, p<.001)$. Remarkably, both clusters behaved opposite from Cluster 1 . Results also showed that learners from Cluster 2 used the sequence '(test made) - (user score)' significantly more $(r=0.39, p<.001)$ than learners in Cluster 1 or three. Learners from Cluster $1(r=1.62, p<.001)$ seemed to prefer to ask questions using the discussion forum before taking a test '(discussion made) - (test made)' more than the other two clusters.

$$
<<\text { FIGURE } 3 \text { >>> }
$$

\subsubsection{School B}

For School B $(n=44)$ the same approach was adopted. Three clusters were identified. A MANOVA showed significant differences between clusters $F(50,30)=15.46, p<.001$; Wilk's $\Lambda=$ 0.001 , partial $\eta^{2}=.96$. One-way ANOVAs indicated that thirteen of the traced variables have significantly different values among clusters (see: figure 4). The analysis indicated that the amount of interaction learners had with information such as (1) the course home page (course viewed) $(F(2,39)$ $=26.067, p=.000$ ), topic pages where the different course topics are delivered (course module viewed) $(F(2,39)=15.255, p=.000)$ and SCORM-packages opened $(F(2,39)=17.958, p=.000) ;(2)$ engagement in discussions (discussion made) $(F(2,39)=6.847, p=.000)$ and on the other hand viewing (discussion viewed) $(F(2,39)=8.288, p=.000)$; (3) formal submission of tasks (test made) $(F$ $(2,39)=65.924, p=.000)$ and assignments (assignment submitted) $(F(2,39)=42.525, p=.000)$; and finally, (4) the consultation of scores (user score) $(F(2,39)=34.565, p=.000)$ and results (submission form consulted) $(F(2,39)=8.249, p=.001)$ seemed to have a different appearance between clusters. Eleven learners belonged to Cluster 1, nineteen to Cluster 2 and twenty-one to Cluster 3 . 
The event sequence analysis (Associated Pearson Residual of the Chi-square test, residuals $\leq-$ 2 less frequent and $\geq 2$ more frequent) showed that learners in Cluster 3 used sequences involving the discussion forum $(r=3.2, p<.001)$ more compared to Cluster $1(r=-1.45, p<.001)$ and two $(r=-$ $1.38, p<.001)$. Learners from Cluster 1 used the sequence '(test made) - (user score)' significantly more $(r=2.52, p<.001)$ than learners from Cluster $3(r=0.96, p<.001)$ and two $(r=-2.67, p<.001)$. These were learners from Cluster $3(r=3.27, p<.001)$ who seemed to prefer to ask questions using the discussion forum before taking a test '(discussion made) - (test made)'. Learners from Cluster 1 ( $r$ $=-1.25, p<.001$ ) did not view the discussion forum before taking a test '(discussion viewed) - (test made)'. Learners in Cluster 2 interacted with the learning environment significantly less than the other two clusters.

\subsubsection{Relation between self-regulation attributes and cluster membership over both schools}

To investigate the relation between cluster membership and the design of BLEs a Chi-square test of independence was calculated (for both schools). This test compared frequencies of cluster membership for the different environments learners were in. Significant interactions were found for both schools, School A $\left(\chi^{2}(6)=28.81, p<.001\right)$ and School B $\left(\chi^{2}(2)=13.85, p=.001\right)$. This result indicates that the environment influences the occurrence of certain profiles. Due to the similar cluster characteristics, significant variables and event sequences, it is reasonable to treat them as comparable. Cluster 1 (School A) and Cluster 3 (School B) were combined in profile one; Cluster 2 (School A) and Cluster 1 (School B) were combined in profile two; and Cluster 3 (School A) and Cluster 2 (School B) were combined in profile three. When the three clusters of each school were matched, a logistic regression was conducted to analyse whether the amount of attributes that support selfregulation in BLEs (sum score per environment) influences the number of learners per profile identified. A test of the full model against a constant only model was significant, indicating that the score for attributes that support self-regulation a course gets influences the amount of learners per profile $(\chi(6)=40.324, p=.025)$. Parameter estimates showed that when the score for self-regulation increases with one point the chance to belong to Cluster 2 (Wald $=4.267, p=.039$ ) or three (Wald = $5.255, p=.022$ ) decreases. $\operatorname{Exp}(B)$ shows that when the score for self-regulation increases with one point, that for both learners in profile two (OR $=0.79$ ( $95 \% \mathrm{Cl} 0.64$ to 0.99$), p=0.039$ ) and three (OR $=0.73(95 \% \mathrm{Cl} 0.64$ to 0.99$), p=0.022$ ) the chance is large (for profile two $21 \%$ and for profile three $27 \%)$ to belong to profile one.

\section{Conclusions and discussion}

The aim of this study was to identify learners' self-regulatory behaviour profiles in BLEs and relate them to the design of the environments. The research involved three major steps: (1) the description of the environments; (2) the identification of the behaviour profiles; and (3) the investigation of the relationships between the previous two.

In the first step, we described six blended learning courses within two Flemish schools (A and B) for adult education, using a framework of self-regulatory attributes. Authenticity, personalization, learner control, scaffolding, and interaction were all observed frequently in the six BLEs. Reflection and calibration cues were least often observed in all of the BLEs. 
Secondly, we identified three similar learner self-regulatory behaviour clusters in the two schools. Each of these clusters relate closely to earlier research done by Vermunt and Vermetten (2004), who identified self-regulating, external regulating and lack of regulation profiles. Cluster 1 (School A) and Cluster 3 (School B) shared the same characteristics. Learners with this profile used a wide diversity of learning resources (content, discussion forum, etc.). Nonetheless, they did not seem to check their scores very often. Learners with this profile seem to prefer to consult the discussion forum. Reflecting on the self-regulation model of Hadwin and Winne (1998), it seems that these learners prefer to evaluate their perceptions and products of learning using resources that can help them generate rich information about their performance. They do not seem to need explicit scores and are able to monitor their own learning and make internal judgements about task success and relative productivity. We named this group 'internal regulators'. These regulators are able to regulate their learning based on feedback of a formative nature.

Cluster 2 (School A) and Cluster 1 (School B) shared the same characteristics. Learners with this profile use the features related to content, assignments, scores, and results. They seem to be very score-oriented. They do interact with content on a moderate basis (significantly less than the internal regulators). They send in assignments and react to messages. They do not interact on the discussion forum, however, but do check their user scores often. Based on the Winne and Hadwin (1998) model, this type of learner seems to favour external evaluation (or binary outcome feedback) arising from performance above formative feedback. As these learners value the outcomes of learning most highly, we named this profile 'external regulators'.

Cluster 3 (School A) and Cluster 2 (School B) were also found to share the same features. The final self-regulatory profile we identified consists of mis-regulating learners. These learners seem to lack direction and do not interact with either embedded or non-embedded instruction. According to the Winne and Hadwin (1998) model, this type of learner deliberately chooses not to participate because they realize that what is asked of them does not match their needs. On the other hand, it is also possible that these learners are unable to regulate their own learning. Our analysis did indeed show that membership of this cluster had a significant negative impact on performance (ANOVA, $F$ $(2,73)=19.880, p=.000)$.

During this second step of the study, it was interesting to note that internal and external regulators seem to focus on different aspects of self-regulation, in line with Butler and Winne (1995). Although there is no evidence in this study that learners with internal regulating profiles struggle more than external regulating profiles or vice versa, some remarks can be made about their differences. First, internally generated feedback is inherent to task engagement (Butler \& Winne, 1995). Such feedback inevitably involves learners' making judgments about both task success and the productivity of various tactics and strategies. Second, the use of outcome feedback to self-regulate provides the least guidance on how to self-regulate (Butler \& Winne, 1995). Its benefits depend very much on learners' being attentive to cues and their own performance during studying, having accurate memories of the learning process when consulting outcome feedback, and being sufficiently strategic to generate effective internal feedback about predictive validities. Figure 5 provides an overview of the differences between the internal and external regulator profiles. 
In the third and final step of the study, we investigated the relationship between the design of the learning environments and the learners' behaviour within those environments. As the sum score on self-regulation increases, the chance of mis-regulators shifting profiles increases significantly. This result indicates that better integration of attributes that support self-regulation in BLEs helps mis-regulators become internal or external regulators. Although neither internal nor external regulators can be classified as better self-regulators, it seems that mis-regulators (based on their behaviour and its relation to performance) are less successful. Therefore, it would be beneficial to increase the extent to which self-regulation attributes are included in the design of BLEs, especially to enable mis-regulators to shift profiles. These results are comparable with previous research on designing learning environments for self-regulation that demonstrates the importance of informed environmental design (e.g., Azevedo \& Hadwin, 2005; Boekaerts \& Corno, 2005; Dabbagh \& Kitsantas, 2004; Schraw, Crippen, \& Hartley, 2006).

This study sheds some light on the relation between BLEs and learners' self-regulatory behaviour, but there are still some issues to overcome. A mixed method approach was used to collect both refined qualitative and quantitative traces. On the qualitative side, we were able to produce very rich descriptions of BLEs. However, the focus on attributes that support self-regulation meant that a considerable number of other variables related to the overall quality of the design (e.g., presentation, demonstration, and application principles) were neglected. First, the process of visualizing the environments, 'scoring' them for occurrence and then reporting on the major observations might have a negative effect on the descriptions' granularity. Second, as the main focus of the study was to identify learners' behaviour in BLEs, rather than the attributes that influence learners' behaviour most and under what circumstances, we used sum scores. This meant, however, that it was impossible to investigate each environment's relationship to the learners' behaviour. Furthermore, the question remains whether it is the quality or the quantity of each attribute that influences this behaviour. Similarly, the quantitative aspect of the study was also influenced by certain limitations. First, the number of participants made it difficult to generalize about the results. Due to feasibility issues, it was not possible to increase the number of courses described or respondents included. On the other hand, though, we saw that the TraMineR package in R-statistics that we used for the event sequence analysis was tested to its limits due to the huge number of traces. This limitation means that, to date, we have only been able to extract event sequences containing two variables per sequence. Finally, research on learning strategies shows that small contextual changes can have a major effect on how learners self-regulate. Keeping this in mind, the grain size of the description tool used to map the BLE might influence the interpretation of the relationships found in this study.

In order to overcome the issues mentioned above, further research is needed to develop the methodology used to identify learners' behaviour in ecological BLEs. A first step might be to refine the grainsize of the instrument used to map both the online and offline learning environments. It would also be beneficial to investigate each of the attributes through an extensive review of the literature and/or to perform interventions to ascertain the relation between each attribute and learners' behaviour. In addition, we would recommend operationalizing the self-regulation concept defined by Hadwin and Winne (1998) and establishing an action library to improve the identification of learners' self-regulation. Such an action library would help to categorize the ecological trace variables into meaningful (coded) variables. By sequencing these variables, more detailed insights 
can be gained into the self-regulatory behaviour of learners. Applying such an approach could improve the reliability of the methodology for measuring learners' self-regulation.

Although this study has its limitations, it suggests innovative approaches to describing and analysing BLEs from a self-regulatory perspective. First, it offers at least a starting point for further research. Others have often failed to describe blended learning designs before and after intervention. Secondly, this study uses learners' actual behavioural traces in the environment rather than learner self-reporting. While there is already some literature on this trend, few studies have favoured ecological data and many prefer pre-designed surveys for gathering trace data (e.g., Azevedo et al., 2010; Harley et al., 2015; Winne, 2016; Winne, 2015; Winne \& Hadwin, 2013; Winne et al., 2006). This study shows in a very modest way that, even in ecological trace data, particular combinations of variables may be able to explain some aspects of learners' self-regulatory behaviour. This data-driven approach might be a promising approach to further inform designs of learning environments. Finally, by relating the designs of BLEs to learners' self-regulatory behaviour in BLEs, a first attempt was made to establish a new perspective on the redesign of BLEs specifically based on learner behaviour. This research adds to the body of research that emphasizes the importance of design for self-regulation. Future research could investigate the more systematic integration of attributes that support self-regulation in BLEs. 


\section{Bibliography}

Agrawal, R., \& Srikant, R. (1995). Mining sequential patterns. Paper presented the Data Engineering, 1995. Proceedings of the Eleventh International Conference on.

Artino, A. R. (2009). Think, feel, act: motivational and emotional influences on military students' online academic success. Journal of Computing in Higher Education, 21(2), 146-166. doi: http://dx.doi.org/10.1007/s12528-009-9020-9

Ausburn, L. J. (2004). Course design elements most valued by adult learners in blended online education environments: An American perspective. Educational Media International, 41(4), 327-337.

Azevedo, R. (2005). Using hypermedia as a metacognitive tool for enhancing student learning? The role of self-regulated learning. Educational Psychologist, 40(4), 199-209.

Azevedo, R., Cromley, J. G., Winters, F. I., Moos, D. C., \& Greene, J. A. (2005). Adaptive human scaffolding facilitates adolescents' self-regulated learning with hypermedia. Instructional Science, 33(5-6), 381-412.

Azevedo, R., \& Hadwin, A. F. (2005). Scaffolding self-regulated learning and metacognitionImplications for the design of computer-based scaffolds. Instructional Science, 33(5), 367-379.

Azevedo, R., Johnson, A., Chauncey, A., \& Burkett, C. (2010). Self-regulated learning with MetaTutor: Advancing the science of learning with MetaCognitive tools New science of learning (pp. 225247): Springer.

Bandura, A. (1989). Human agency in social cognitive theory. American psychologist, 44(9), 1175.

Bannert, M. (2009). Promoting self-regulated learning through prompts. Zeitschrift für Pädagogische Psychologie, 23(2), 139-145.

Barnard, L., Lan, W. Y., To, Y. M., Paton, V. O., \& Lai, S.-L. (2009). Measuring self-regulation in online and blended learning environments. The Internet and Higher Education, 12(1), 1-6.

Belfiore, P. J., \& Hornyak, R. (1998). Operant theory and application to self-monitoring in adolescents. Self-regulated learning: From teaching to self-reflective practice, 184-202.

Bennet, S., Harper, B., \& Hedberg, J. (2002). Designing real life cases to support authentic design activities. Australasian Journal of Educational Technology, 18(1).

Benson, P. (2013). Teaching and researching: Autonomy in language learning: Routledge.

Bersin, J., \& others. (2003). What works in blended learning. Learning circuits.

Biemiller, A., Shany, M., Inglis, A., \& Meichenbaum, D. (1998). Factors influencing children's acquisition and demonstration of self-regulation on academic tasks. Self-regulated learning: From teaching to self-reflective practice, 203-224.

Boekaerts, M., \& Corno, L. (2005). Self-regulation in the classroom: A perspective on assessment and intervention. Applied Psychology, 54(2), 199-231.

Boelens, R., Van Laer, S., De Wever, B., \& Elen, J. (2015). Blended learning in adult education: towards a definition of blended learning.

Bol, L., \& Garner, J. K. (2011). Challenges in supporting self-regulation in distance education environments. Journal of Computing in Higher Education, 23(2-3), 104-123.

Bonk, C. J., \& Graham, C. R. (2012). The handbook of blended learning: Global perspectives, local designs: John Wiley \& Sons.

Boud, D., Keogh, R., \& Walker, D. (2013). Reflection: Turning experience into learning: Routledge.

Bransford, J. D., Vye, N., Kinzer, C., \& Risko, V. (1990). Teaching thinking and content knowledge: Toward an integrated approach. Dimensions of thinking and cognitive instruction, 1.

Brookfield, S. (1986). Understanding and facilitating adult learning: A comprehensive analysis of principles and effective practices: McGraw-Hill Education (UK).

Brown, J. S., Collins, A., \& Duguid, P. (1989). Situated cognition and the culture of learning. Educational researcher, 18(1), 32-42.

Butler, D. L. (1998). The strategic content learning approach to promoting self-regulated learning: A report of three studies. Journal of Educational Psychology, 90(4), 682. 
Butler, D. L., \& Winne, P. H. (1995). Feedback and Self-Regulated Learning: A Theoretical Synthesis. Review of Educational Research, 65(3), 245-281. doi: http://dx.doi.org/10.2307/1170684

Caffarella, R., \& Merriam, S. B. (2000). Linking the individual learner to the context of adult learning. Handbook of adult and continuing education, 55-70.

Cennamo, K. S., Ross, J. D., \& Rogers, C. S. (2002). Evolution of a Web-Enhanced Course: Incorporating Strategies for Self-Regulation. Educause Quarterly, 25(1), 28-33.

Cicchetti, D. V. (1994). Guidelines, criteria, and rules of thumb for evaluating normed and standardized assessment instruments in psychology. Psychological assessment, 6(4), 284.

Collins, A., Brown, J. S., \& Newman, S. E. (1989). Cognitive apprenticeship: Teaching the crafts of reading, writing, and mathematics. Knowing, learning, and instruction: Essays in honor of Robert Glaser, 18, 32-42.

Collis, B., Bruijstens, H., \& van Veen, J. K. d. (2003). Course redesign for blended learning: Modern optics for technical professionals. International Journal of Continuing Engineering Education and Life Long Learning, 13(1-2), 22-38.

Connolly, C., Murphy, E., \& Moore, S. (2007). Second Chance Learners, Supporting Adults Learning Computer Programming. Paper presented at the International Conference on Engineering Education-ICEE.

Cordova, D. I., \& Lepper, M. R. (1996). Intrinsic motivation and the process of learning: Beneficial effects of contextualization, personalization, and choice. Journal of Educational Psychology, $88(4), 715$.

Corno, L. (1995). Comments on Winne: Analytic and systemic research are both needed. Educational Psychologist, 30(4), 201-206.

Dabbagh, N., \& Kitsantas, A. (2004). Supporting self-regulation in student-centered web-based learning environments. International Journal on E-Learning, 3(1), 40-47.

De Wever, B., Schellens, T., Valcke, M., \& Van Keer, H. (2006). Content analysis schemes to analyze transcripts of online asynchronous discussion groups: A review. Computers \& Education, 46(1), 6-28.

Devedžić, V. (2006). Semantic Web and Education, Volume 12 of Integrated series in Information Systems./Vladan Devedžić: Springer.

Dewey, J. (1958). Experience and nature (Vol. 1): Courier Corporation.

Driscoll, M. (2002). Blended learning: Let's get beyond the hype. E-learning, 1.

Edelson, D. C., Gordin, D. N., \& Pea, R. D. (1999). Addressing the challenges of inquiry-based learning through technology and curriculum design. Journal of the Learning Sciences, 8(3-4), 391-450.

Edelson, D. C., Pea, R. D., \& Gomez, L. (1996). Constructivism in the collaborator. Constructivist learning environments: Case studies in instructional design, 151-164.

Endedijk, M. D., Brekelmans, M., Sleegers, P., \& Vermunt, J. D. (2015). Measuring students' selfregulated learning in professional education: bridging the gap between event and aptitude measurements. Quality \& Quantity, 1-24.

Farrall, S. (2007). Desistance studies vs. cognitive-behavioural therapies: Which offers most hope for the long term. Dictionary of Probation and Offender Management. Cullompton: Willan Publishing, 178.

Gabadinho, A., Ritschard, G., Mueller, N. S., \& Studer, M. (2011). Analyzing and visualizing state sequences in $\mathrm{R}$ with TraMineR. Journal of Statistical Software, 40(4), 1-37.

Garrison, D. R., \& Kanuka, H. (2004). Blended learning: Uncovering its transformative potential in higher education. The Internet and Higher Education, 7(2), 95-105. doi: http://dx.doi.org/10.1016/j.iheduc.2004.02.001

Garrison, D. R., \& Vaughan, N. D. (2008). Blended learning in higher education: Framework, principles, and guidelines: John Wiley \& Sons.

Garza, R. (2009). Latino and White High School Students' Perceptions of Caring Behaviors Are We Culturally Responsive to our Students? Urban Education, 44(3), 297-321.

Graham, C. R. (2006). Blended learning systems. CJ Bonk \& CR Graham, The handbook of blended learning: Global perspectives, local designs. Pfeiffer. 
Graham, S., Harris, K. R., \& Troia, G. A. (1998). Writing and self-regulation: Cases from the selfregulated strategy development model. Self-regulated learning: From teaching to selfreflective practice, $20-41$.

Gray, S. J. (1988). Towards a theory of cultural influence on the development of accounting systems internationally. Abacus, 24(1), 1-15.

Greene, J. A., \& Azevedo, R. (2007). A Theoretical Review of Winne and Hadwin's Model of SelfRegulated Learning: New Perspectives and Directions. Review of Educational Research, 77(3), 334-372. doi: http://dx.doi.org/10.3102/003465430303953

Grimmett, P. P., \& Neufeld, J. (1994). Teacher development and the struggle for authenticity: Professional growth and restructuring in the context of change: Teachers College Press New York.

Hadwin, A. F., Nesbit, J. C., Jamieson-Noel, D., Code, J., \& Winne, P. H. (2007). Examining trace data to explore self-regulated learning. Metacognition and Learning, 2(2-3), 107-124.

Hansman, C. (2008). Adult learning in communities of practice. Communities of Practice, 1, 293-310.

Harley, J. M., Bouchet, F., Hussain, M. S., Azevedo, R., \& Calvo, R. (2015). A multi-componential analysis of emotions during complex learning with an intelligent multi-agent system. Computers in Human Behavior, 48, 615-625.

Harrison, M. (2003). Blended learning in practice.

Hatton, N., \& Smith, D. (1995). Reflection in teacher education: Towards definition and implementation. Teaching and Teacher Education, 11(1), 33-49.

Herrington, J. (2005). Authentic learning environments in higher education: IGI Global.

Herrington, J., Oliver, R., \& Reeves, T. C. (2003). Patterns of engagement in authentic online learning environments. Australasian Journal of Educational Technology, 19(1).

Hiemstra, R. (1993). Three underdeveloped models for adult learning. New directions for adult and continuing education, 1993(57), 37-46.

Hillman, D. C., Willis, D. J., \& Gunawardena, C. N. (1994). Learner-interface interaction in distance education: An extension of contemporary models and strategies for practitioners. American Journal of Distance Education, 8(2), 30-42.

Hofer, B., Yu, S., \& Pintrich, P. (1998). Teaching college students to be self-regulated learners. In. DH Schunk \& BJ Zimmerman (Eds.), Self-regulated learning: From teaching to self-reflective practice (pp. 57-83): New York: The Guilford Press.

Honebein, P. C., Duffy, T. M., \& Fishman, B. J. (1993). Constructivism and the design of learning environments: Context and authentic activities for learning Designing environments for constructive learning (pp. 87-108): Springer.

Hooper, S. (1992). Cooperative learning and computer-based instruction. Educational Technology Research and Development, 40(3), 21-38.

House, R. (2002). Clocking in column. The Spokesman-Review.

Ifenthaler, D. (2012). Determining the effectiveness of prompts for self-regulated learning in problemsolving scenarios. Educational Technology \& Society, 15(1), 38-52.

Järvelä, S., Järvenoja, H., \& Malmberg, J. (2012). How elementary school students' motivation is connected to self-regulation. Educational Research and Evaluation, 18(1), 65-84.

Jorgensen, D. L. (1989). Participant observation: Wiley Online Library.

Keller, J. M. (2010). Motivational Design for Learning and Performance. Boston, MA: Springer US.

Knowles, M. S., Holton, E. F., \& Swanson, R. A. (2014). The adult learner: The definitive classic in adult education and human resource development: Routledge.

Kolodner, J. L., Owensby, J. N., \& Guzdial, M. (2004). Case-based learning aids. Handbook of research on educational communications and technology, 2, 829-861.

Lajoie, S. P. (2005). Extending the scaffolding metaphor. Instructional Science, 33(5-6), 541-557.

Laurillard, D. (1987). Computers and the emancipation of students: giving control to the learner. Instructional Science, 16(1), 3-18. 
Lebow, D. G., \& Wager, W. W. (1994). Authentic Activity as a Model for Appropriate Learning Activity: Implications for Emerging Instructional Technologies. Canadian Journal of Educational Communication, 23(3), 231-244.

Ley, K., \& Young, D. B. (2001). Instructional principles for self-regulation. Educational Technology Research and Development, 49(2), 93-103.

Lin, B., \& Hsieh, C.-t. (2001). Web-based teaching and learner control: A research review. Computers \& Education, 37(3), 377-386.

Linn, R. L., Baker, E. L., \& Dunbar, S. B. (1991). Complex, performance-based assessment: Expectations and validation criteria. Educational researcher, 20(8), 15-21.

Lynch, R., \& Dembo, M. (2004a). The relationship between self-regulation and online learning in a blended learning context. The International Review of Research in Open and Distributed Learning, 5(2).

Lynch, R., \& Dembo, M. (2004b). The relationship between self-regulation and online learning in a blended learning context. The International Review of Research in Open and Distance Learning, 5.

Manlove, S., Lazonder, A. W., \& de Jong, T. (2007). Software scaffolds to promote regulation during scientific inquiry learning. Metacognition and Learning, 2(2-3), 141-155.

Mann, K., Gordon, J., \& MacLeod, A. (2009). Reflection and reflective practice in health professions education: a systematic review. Advances in Health Sciences Education, 14(4), 595-621.

Martinez, M. (2002). Designing learning objects to personalize learning. The instructional use of learning objects, 151-171.

Merrill, M. D. (2002). First principles of instruction. Educational Technology Research and Development, 50(3), 43-59. doi: http://dx.doi.org/10.1007/Bf02505024

Milheim, W. D., \& Martin, B. L. (1991). Theoretical bases for the use of learner control: Three different perspectives. Journal of computer-based instruction.

Moon, J. (1999). Reflection in learning and professional development. Abingdon, Oxon: RoutledgeFalmer.

Moore, M. G. (1989). Editorial: Three types of interaction.

Munby, H., \& Russell, T. (1992). Frames of reflection: An introduction. Teachers and teaching: From classroom to reflection, 1-8.

Nietfeld, J. L., Cao, L., \& Osborne, J. W. (2006). The effect of distributed monitoring exercises and feedback on performance, monitoring accuracy, and self-efficacy. Metacognition and Learning, 1(2), 159-179.

Nordlund, M., Bonfanti, S., \& Strandh, M. (2015). Second chance education matters! Income trajectories of poorly educated non-Nordics in Sweden. Journal of Education and Work, 28(5), 528-550.

Oliver, M., \& Trigwell, K. (2005). Can 'blended learning'be redeemed. E-learning, 2(1), 17-26. doi: http://dx.doi.org/10.2304/elea.2005.2.1.17

Orey, M. (2002a). Definition of blended learning. University of Georgia. Retrieved February, 21, 2003.

Orey, M. (2002b, 2002). One year of online blended learning: Lessons learned.

Perry, N. E., \& Winne, P. H. (2006). Learning from learning kits: gStudy traces of students' self-regulated engagements with computerized content. Educational Psychology Review, 18(3), 211-228.

Petraglia, J. (1998). Reality by design: The rhetoric and technology of authenticity in education: Routledge.

Pintrich, P. R. (2004). A conceptual framework for assessing motivation and self-regulated learning in college students. Educational Psychology Review, 16(4), 385-407.

Pintrich, P. R., Smith, D. A., García, T., \& McKeachie, W. J. (1993). Reliability and predictive validity of the Motivated Strategies for Learning Questionnaire (MSLQ). Educational and Psychological Measurement, 53(3), 801-813.

Pressley, M., El-Dinary, P., Wharton-McDonald, R., \& Brown, R. (1998). Transactional instruction of comprehension strategies in the elementary grades. In DH Schunk \& BJ Zimmerman (Eds.), 
Self-regulated learning: From research to self-reflective practice (Pp. 42-56). New York: Guilford.

Puntambekar, S., \& Hubscher, R. (2005). Tools for scaffolding students in a complex learning environment: What have we gained and what have we missed? Educational Psychologist, 40(1), 1-12.

Reay, J. (2001). Blended learning-a fusion for the future. Knowledge Management Review, 4, 6.

Reeves, T. C., \& Okey, J. R. (1996). Alternative assessment for constructivist learning environments. Constructivist learning environments: Case studies in instructional design, 191-202.

Reeves, T. C., \& Reeves, P. M. (1997). Effective dimensions of interactive learning on the World Wide Web. Web-based instruction, 59-66.

Reigeluth, C. M. (1999). What is instructional-design theory and how is it changing. Instructional-design theories and models: A new paradigm of instructional theory, 2, 5-29.

Reiser, B. J. (2004). Scaffolding complex learning: The mechanisms of structuring and problematizing student work. The Journal of the Learning Sciences, 13(3), 273-304.

Rooney, J. E. (2003). Knowledge infusion. Association Management, 55, 26-32.

Rossett, A. (2002). The ASTD e-learning handbook: Best practices, strategies, and case studies for an emerging field: McGraw-Hill Trade.

Roth, W.-M., \& Bowen, G. M. (1995). Knowing and interacting: A study of culture, practices, and resources in a grade 8 open-inquiry science classroom guided by a cognitive apprenticeship metaphor. Cognition and Instruction, 13(1), 73-128.

Sands, P. (2002). Inside outside, upside downside. Strategies, 8.

Sansone, C., Fraughton, T., Zachary, J. L., Butner, J., \& Heiner, C. (2011). Self-regulation of motivation when learning online: the importance of who, why and how. Etr\&D-Educational Technology Research and Development, 59(2), 199-212. doi: http://dx.doi.org/10.1007/s11423-011-9193$\underline{6}$

Scheiter, K., \& Gerjets, P. (2007). Learner control in hypermedia environments. Educational Psychology Review, 19(3), 285-307.

Schön, D. A. (1987). Educating the reflective practitioner: Toward a new design for teaching and learning in the professions. San Francisco.

Schraw, G., Crippen, K. J., \& Hartley, K. (2006). Promoting self-regulation in science education: Metacognition as part of a broader perspective on learning. Research in Science Education, 36(1-2), 111-139.

Schunk, D. H. (1998). Teaching elementary students to self-regulate practice of mathematical skills with modeling.

Schunk, D. H., \& Zimmerman, B. J. (1994). Self-regulation of learning and performance: Issues and educational applications: Lawrence Erlbaum Associates, Inc.

Sharma, S., Dick, G., Chin, W. W., \& Land, L. (2007). Self-Regulation and E-Learning. Paper presented at the ECIS.

Sims, R., \& Hedberg, J. (1995). Dimensions of Learner Control A Reappraisal for Interactive Multimedia Instruction.

Singh, H., Reed, C., \& others. (2001). A white paper: Achieving success with blended learning. Centra software, 1 .

Smith, G. G., \& Kurthen, H. (2007). Front-stage and back-stage in hybrid e-learning face-to-face courses. International Journal on E-Learning, 6(3), 455-474.

Spanjers, I. A., Könings, K. D., Leppink, J., Verstegen, D. M., de Jong, N., Czabanowska, K., \& Van Merriënboer, J. J. (2015). The promised land of blended learning: Quizzes as a moderator. Educational Research Review. doi: http://dx.doi.org/10.1016/i.edurev.2015.05.001

Sutton, L. A. (2001). The principle of vicarious interaction in computer-mediated communications. International Journal of Educational Telecommunications, 7(3), 223-242.

Swanson, H. L., \& Lussier, C. M. (2001). A selective synthesis of the experimental literature on dynamic assessment. Review of Educational Research, 71(2), 321-363. 
Thiede, K. W., Anderson, M., \& Therriault, D. (2003). Accuracy of metacognitive monitoring affects learning of texts. Journal of Educational Psychology, 95(1), 66.

Thiede, K. W., \& Dunlosky, J. (1994). Delaying students' metacognitive monitoring improves their accuracy in predicting their recognition performance. Journal of Educational Psychology, 86(2), 290.

Thomson, I. (2002). Thomson job impact study: The next generation of corporate learning. Retrieved July, 7, 2003.

Tough, A. (1978). Major learning efforts: Recent research and future directions. Adult Education Quarterly, 28(4), 250-263.

Van Laer, S., \& Elen, J. (2016). In search of attributes that support self-regulation in blended learning environments. Education and Information Technologies, 1-60.

van Merriënboer, J. J. G., \& Kirschner, P. A. (2001). Three worlds of instructional design: State of the art and future directions. Instructional Science, 29(4-5), 429-441.

Veenman, M. V., Van Hout-Wolters, B. H., \& Afflerbach, P. (2006). Metacognition and learning: Conceptual and methodological considerations. Metacognition and Learning, 1(1), 3-14.

Vermunt, J. D., \& Vermetten, Y. J. (2004). Patterns in student learning: Relationships between learning strategies, conceptions of learning, and learning orientations. Educational Psychology Review, 16(4), 359-384.

Ward, J., \& LaBranche, G. A. (2003). Blended learning: The convergence of e-learning and meetings. Franchising World, 35, 22-24.

Weinstein, C. E., Zimmerman, S., \& Palmer, D. (1988). Assessing learning strategies: The design and development of the LASSI. Learning and study strategies: Issues in assessment, instruction, and evaluation, 25-40.

Wesiak, G., Steiner, C. M., Moore, A., Dagger, D., Power, G., Berthold, M., . . Conlan, O. (2014). Iterative augmentation of a medical training simulator: Effects of affective metacognitive scaffolding. Computers \& Education, 76(0), 13-29. doi: http://dx.doi.org/10.1016/i.compedu.2014.03.004

Whitelock, D., \& Jelfs, A. (2003). Editorial for special issue on blended learning: Blending the issues and concerns of staff and students. Journal of Educational Media, 28, 99-100.

Wiggins, G. P. (1993). Assessing student performance: Exploring the purpose and limits of testing: Jossey-Bass.

Williams, M. D. (1993). A Comprehensive Review of Learner-Control: The Role of Learner Characteristics.

Wilson, S., Liber, O., Johnson, M. W., Beauvoir, P., Sharples, P., \& Milligan, C. D. (2007). Personal Learning Environments: Challenging the dominant design of educational systems. Journal of $E$ Learning and Knowledge Society, 3(2), 27-38.

Winne, P. (2016). Self-regulated learning. SFU Educational Review, 1(1).

Winne, P. H. (1982). Minimizing the black box problem to enhance the validity of theories about instructional effects. Instructional Science, 11(1), 13-28. doi: http://dx.doi.org/10.1007/Bf00120978

Winne, P. H. (1985). Steps toward promoting cognitive achievements. The Elementary School Journal, 85(5), 673-693. doi: http://dx.doi.org/10.1086/461429

Winne, P. H. (1995). Inherent details in self-regulated learning. Educational Psychologist, 30(4), 173187. doi: http://dx.doi.org/10.1207/s15326985ep3004 2

Winne, P. H. (1996). A metacognitive view of individual differences in self-regulated learning. Learning and Individual Differences, 8(4), 327-353. doi: http://dx.doi.org/10.1016/S1041$\underline{6080(96) 90022-9}$

Winne, P. H. (2006). Handbook of educational psychology: Psychology Press.

Winne, P. H. (2015). What is the state of the art in self-, co-and socially shared regulation in CSCL? Computers in Human Behavior, 52, 628-631. 
Winne, P. H., \& Hadwin, A. (2013). nStudy: Tracing and Supporting Self-Regulated Learning in the Internet. In R. Azevedo \& V. Aleven (Eds.), International Handbook of Metacognition and Learning Technologies (Vol. 28, pp. 293-308): Springer New York.

Winne, P. H., \& Hadwin, A. F. (1998). Studying as self-regulated learning. Metacognition in educational theory and practice, 93, 27-30.

Winne, P. H., \& Marx, R. W. (1989). A cognitive-processing analysis of motivation within classroom tasks. Research on motivation in education, 3, 223-257.

Winne, P. H., Nesbit, J. C., Kumar, V., Hadwin, A. F., Lajoie, S. P., Azevedo, R., \& Perry, N. E. (2006). Supporting self-regulated learning with gStudy software: The Learning Kit Project. Technology Instruction Cognition and Learning, 3(1/2), 105.

Winne, P. H., \& Perry, N. E. (2000). Measuring self-regulated learning.

Winne, P. H., \& Stockley, D. B. (1998). Computing technologies as sites for developing self-regulated learning. Self-regulated learning: From teaching to self-reflective practice, 106-136.

Woo, Y., \& Reeves, T. C. (2007). Meaningful interaction in web-based learning: A social constructivist interpretation. The Internet and Higher Education, 10(1), 15-25.

Wood, E., Woloshyn, V., \& Willoughby, T. (1995). Cognitive strategy instruction for middle and high schools: Brookline Books.

Young, J. R. (2001). " Hybrid" Teaching Seeks To End the Divide between Traditional and Online Instruction. The Chronicle of Higher Education.

Young, M. F. (1993). Instructional design for situated learning. Educational Technology Research and Development, 41(1), 43-58.

Zaki, M. J. (2001). SPADE: An efficient algorithm for mining frequent sequences. Machine learning, 42(1-2), 31-60.

Zimmerman, B. J. (2008). Investigating self-regulation and motivation: Historical background, methodological developments, and future prospects. American Educational Research Journal, 45(1), 166-183.

Zimmerman, B. J., \& Schunk, D. H. (2001). Self-regulated learning and academic achievement: Theoretical perspectives: Routledge. 


\section{Appendix 1: Questions per attribute}

\begin{tabular}{|c|c|c|}
\hline Attributes & Main question & Sub question \\
\hline Authenticity & $\begin{array}{l}\text { Does the learning environment contain } \\
\text { authentic real-world relevance? }\end{array}$ & $\begin{array}{l}\text { - Is an authentic context provided that reflect the way the knowledge will be used in real life? } \\
\text { - Are authentic activities provided? } \\
\text { - Is there access to expert performances and the modelling of processes? } \\
\text { - } \text { - Is there support for collaborative construction of knowledge? } \\
\text { - Is articulation provided to enable tacit knowledge to be made explicit? } \\
\text { - Is authentic assessment of learning provided within the tasks? }\end{array}$ \\
\hline Personalization & $\begin{array}{l}\text { Does the learning environment contain } \\
\text { personalization? }\end{array}$ & $\begin{array}{l}\text { - Is the personalization name-recognized? } \\
\text { - Is the personalization self-described? } \\
\text { - Is the personalization cognitive-based? }\end{array}$ \\
\hline Learner-control & $\begin{array}{l}\text { Does the learning environment allow } \\
\text { learner control? }\end{array}$ & $\begin{array}{l}\text { - Is control of pacing allowed? } \\
\text { - Is control of content allowed? } \\
\text { - Is control of learning activities allowed? } \\
\text { - Is control of content sequence allowed? }\end{array}$ \\
\hline Scaffolding & $\begin{array}{l}\text { Does the learning environment scaffold } \\
\text { support? }\end{array}$ & $\begin{array}{l}\text { - Is support tailored to the learner through continuous monitoring? } \\
\text { - } \quad \text { Does the support fade over time? } \\
\text { - Is there a transfer of responsibilities over time? }\end{array}$ \\
\hline Interaction & $\begin{array}{l}\text { Does the learning environment entail } \\
\text { interaction? }\end{array}$ & $\begin{array}{l}\text { - Is learner-content interaction facilitated? } \\
\text { - Is learner-instructor interaction facilitated? } \\
\text { - Is learner-learner interaction facilitated? } \\
\text { - Is learner-interface interaction facilitated? } \\
\text { - Is vicarious interaction facilitated? }\end{array}$ \\
\hline Reflection cues & $\begin{array}{l}\text { Does the learning environment contain } \\
\text { reflection cues? }\end{array}$ & $\begin{array}{l}\text { - Does the reflection-for-action approach apply? } \\
\text { - Does the reflection-in-action approach apply? } \\
\text { - Does the reflection-on-action approach apply? }\end{array}$ \\
\hline Calibration cues & $\begin{array}{l}\text { Does the learning environment contain } \\
\text { calibration cues? }\end{array}$ & $\begin{array}{l}\text { - Is a strategy applied to guide learners to delay metacognitive monitoring? } \\
\text { - Is a strategy applied for the provision of forms that guide students to summarize content? } \\
\text { - Ire timed alerts given that guide students to summarize content? } \\
\text { - Is a strategy applied for helping learners review the 'right' information? } \\
\text { on past tests as well as items (or tasks) on those tests? }\end{array}$ \\
\hline
\end{tabular}




\section{Appendix 2: Manual for scoring attributes}

\section{Authenticity}

The use of the word authentic is open to interpretation. A sustainable amount of attempts to define this concept transparently is done (see e.g., Bennet, Harper, \& Hedberg, 2002; Herrington, 2005; Wesiak et al., 2014). Definitions range from real-world relevance (Wesiak et al., 2014), needed in reallife situations (Sansone, Fraughton, Zachary, Butner, \& Heiner, 2011) and of important interest of the learner for later professional life (Grimmett \& Neufeld, 1994) to models that focus on applying conceptual knowledge or skills, such as critical thinking or problem solving (Young, 1993). Based on their literature review Van Laer and Elen (2016) defined authenticity as the real-world relevance (both to the learners' professional and personal life) of on the one hand the learning environment (e.g., Herrington, Oliver, \& Reeves, 2003; Petraglia, 1998; Roth \& Bowen, 1995) and on the other hand the task (e.g., Merrill, 2002; Reigeluth, 1999; van Merriënboer \& Kirschner, 2001). Guidance question for identifying authenticity in learning environments and learning tasks are:

- 1.1. Authentic context. Is an authentic context provided that reflect the way the knowledge will be used in real life? In designing online learning environments with authentic contexts, it is not enough to simply provide suitable examples from real-world situations to illustrate the concept or issue being taught. The context needs to be all-embracing, to provide the purpose and motivation for learning, and to provide a sustained and complex learning environment that can be explored at length (e.g., Brown, Collins, \& Duguid, 1989; Honebein, Duffy, \& Fishman, 1993; Reeves \& Reeves, 1997).

- 1.2. Authentic activities. Are authentic activities provided? The learning environment needs to provide ill-defined activities which have real-world relevance, and which present a single complex task to be completed over a sustained period of time, rather than a series of shorter disconnected examples (e.g., Bransford, Vye, Kinzer, \& Risko, 1990; Lebow \& Wager, 1994).

- 1.3. Expert performance. Is there access to expert performances and the modelling of processes? In order to provide expert performances, the environment needs to provide access to expert thinking and the modelling of processes, access to learners in various levels of expertise, and access to the social periphery or the observation of real-life episodes as they occur (Collins, Brown, \& Newman, 1989).

- 1.4. Multiple roles. Are there multiple roles and perspectives provided? In order for students to be able to investigate the learning environment from more than a single perspective, it is important to enable and encourage students to explore different perspectives on the topics from various points of view, and to 'criss cross' the learning environment repeatedly (Collins et al., 1989).

- 1.5. Collaborative knowledge construction. Is there support for collaborative construction of knowledge? The opportunity for users to collaborate is an important design element, particularly for students who may be learning at a distance. Consequently, tasks need to be addressed to a group rather than an individual, and appropriate means of communication need to be established. Collaboration can be encouraged through appropriate tasks and communication technology (e.g., discussion boards, chats, email, debates etc.) (e.g., Hooper, 1992).

- 1.6. Tacit knowledge made explicit. Is articulation provided to enable tacit knowledge to be made explicit? In order to produce a learning environment capable of providing opportunities for 
articulation, the tasks need to incorporate inherent opportunities to articulate, collaborative groups to enable articulation, and the public presentation of argument to enable defense of the position (e.g., Edelson, Pea, \& Gomez, 1996).

- 1.7. Authentic assessment. Is authentic assessment of learning within the tasks provided? In order to provide integrated and authentic assessment of student learning, the learning environment needs to provide: the opportunity for students to be effective performers with acquired knowledge, and to craft polished, performances or products in collaboration with others. It also requires the assessment to be seamlessly integrated with the activity, and to provide appropriate criteria for scoring varied products (e.g., Linn, Baker, \& Dunbar, 1991; Reeves \& Okey, 1996; Wiggins, 1993).

\section{Personalization}

Personalization is often described as non-homogenous experiences related directly to the learner (Wilson et al., 2007), associated with characters and objects of inherent interest to the learner and connects with topics of high interest value (Cordova \& Lepper, 1996). Similar to these views on personalization, based on their literature review, Van Laer and Elen (2016) defined personalization as the modification of the learning environment to the inherent needs of each individual learner. Five major questions were raised by the current literature on the use of personalized learning environments (Devedžić, 2006; Martinez, 2002). These questions are:

- 2.1. Name-recognition. Is the personalization name-recognized? This type of personalization aims at the acknowledgement of the learner as an individual. For example, the learner's name can appear in the instruction or previous activities or accomplishments that have been collected and stored can later be presented when appropriate.

- 2.2. Self-described. Is the personalization self-described? Self-described personalization enables learners, (using questionnaires, surveys, registration forms, and comments) to describe preferences and common attributes. For example, learners may take a pre-course quiz to identify existing skills, preferences, or past experiences. Afterwards, options and instructional experiences appear based on the learner-provided answers.

- 2.3. Cognition-based. Is the personalization cognitive-based? Cognitive-based personalization uses information about cognitive processes, strategies, and ability to deliver content specifically targeted to specific types (defined cognitively) of learners. For example, learners may choose to use an audio option because they prefer hearing text rather than reading it. Or, a learner may prefer the presentation of content in a linear fashion, rather than an unsequenced presentation with hyperlinks.

\section{Learner-control}

Learner-control refers to the amount of control learners have over support in BLEs. Different researchers identify different kinds of learner-control. Varying from freedom of task-selection by the learner (Artino, 2009), control of learning sequences (sequence control) (Lin \& Hsieh, 2001), allowing decisions on which contents to receive (selection or content control), allowing decisions on how a specific content should be displayed (representation control) and control over the pace of information presentation (Scheiter \& Gerjets, 2007). Van Laer and Elen (2016), based on their literature review, defined learner-control as an inclusive approach based on the earlier mentioned different kinds of 
learner-control. Therefor learner control is a concept where learners have or have not control over the pacing, content, learning activities and content sequence. Four major questions (Williams, 1993) occur when describing learner-control in learning environments:

- 3.1. Control over pacing. Is control of pacing allowed (Sims \& Hedberg, 1995)? These traces suggest that the learners have control over the speed of presentation of instructional materials. Another element considered is the ability to control pacing, is the speed and time at which content is presented.

- 3.2. Control over content. Is control of content allowed (Milheim \& Martin, 1991)? These traces suggest that the learner is permitted to skip over certain instructional units. This option generally refers to the selection of topics or objectives associated with a specific lesson, although it does not extend to a choice of which content items are displayed. This component of learner control does not focus on the micro level of interaction, in which the learner must make certain choices in response to questions or problems. Therefore, while the learner has control over the content selected for study, the actual presentation of that content has generally remained instructor driven. Thus, there would appear to be two levels of content control-that where the learner chooses a module of study, and that where the presentation and associated display elements are also under learner control.

- 3.3. Control over learning activities. Is control of learning activities allowed (Laurillard, 1987)? This includes options for the student to see examples, do exercises, receive information, consult a glossary, ask for more explanation, and take a quiz.

- 3.4. Control over content sequence. Is of control of content sequence allowed? This includes provisions for the student to skip forward or backward a chosen amount or to retrace a route through the material, and options to control when to view such features as content indexes or content maps. Sequence control refers to the order in which the content is viewed, and often is defined in terms of being able to move to and fro among content items, such as those described by Gray (1988).

\section{Scaffolding}

Many different approaches to scaffolding have emerged from the design research on interactive learning environments, and a variety of design guidelines or principles have been proposed (Edelson, Gordin, \& Pea, 1999; Kolodner, Owensby, \& Guzdial, 2004). Based on their literature review Van Laer and Elen (2016) define scaffolding as changes in the task, so learners can accomplish tasks that would otherwise be out of their reach (Reiser, 2004). This definition of scaffolding is reflected by three major questions (Puntambekar \& Hubscher, 2005):

- 4.1. Contingency. Is support tailored to the learner through continuous monitoring? The support must be adapted to the current level of the learners' performance and should either be at the same or a slightly higher level. A tool for contingency is diagnostic strategies. To provide this support, one must first determine the learners' current level of competence. Many authors have acknowledged the importance of diagnosis in relation to scaffolding (e.g., Garza, 2009; Lajoie, 2005; Swanson \& Lussier, 2001).

- 4.2. Fading over time. Does the support fade over time? Fading depends upon the learners' level of development and competence. Support fades when the level and/or the amount decreases over time. 
- 4.3. Transfer of responsibility. Is there a transfer of responsibilities over time? Responsibility for the performance of a task is gradually transferred to the learner. Responsibility can refer both to cognitive and metacognitive activities and to learners' affect. The responsibility for learning is transferred when a student takes increasing learner control.

\section{Interaction}

The nature of interaction in various forms of learning environments has been defined in a variety of ways, based upon the participants' level of involvement in a specific learning opportunity and the objects of interaction such as other participants or content materials. The nature of interaction is also dependent upon the contexts in which interaction occurs, in a face-to-face situation or at a distance. Van Laer and Elen (2016) describe interaction as the involvement of learners with elements in the learning environment. Five major interaction related questions are taken into account (Woo \& Reeves, 2007):

- 5.1. Learner-content interaction. Is learner-content interaction facilitated (Hiemstra, 1993)? The first type of interaction is interaction between the learner and the content or subject of study. They are often one-way communications with a subject expert, intended to help learners in their study of the subject.

- 5.2. Learner-instructor interaction. Is learner-instructor interaction facilitated (Moore, 1989)? The second type of interaction is learners-instructor interaction between the learner and the expert who prepared the subject material, or some other expert acting as an instructor.

- 5.3. Learner-learner interaction. Is learner-learner interaction facilitated (Moore, 1989)? The third form of interaction is the inter-learner interaction, between one learner and other learners, alone or in group settings, with or without the real-time presence of an instructor.

- 5.4. Learner-interface interaction. Is learner-interface interaction facilitated (Hillman, Willis, \& Gunawardena, 1994)? The fourth type of interaction is learner-interface interaction, which describes the interaction between the learner and the tools needed to perform the required task.

- 5.5. Vicarious interaction. Is vicarious interaction facilitated (Sutton, 2001)? This final type of interaction takes place when a student actively observes and processes both sides of a direct interaction between two other students or between another student and the instructor.

\section{Reflection-cues}

Many different definitions of reflection have been proposed over time. Dewey (1958) defined reflection as "active, persistent and careful consideration of any belief or supposed form of knowledge in the light of the grounds that support it and the further conclusion to which it tends" (p. 9). Moon (1999) describes reflection as "a form of mental processing with a purpose and/or anticipated outcome that is applied to relatively complex or unstructured ideas for which there is not an obvious solution" (p. 23). Boud, Keogh, and Walker (2013) define reflection as "a generic term for those intellectual and affective activities in which individuals engage to explore their experiences in order to lead to a new understanding and appreciation" (p. 19). All three definitions emphasize purposeful critical analysis of knowledge and experience, in order to achieve deeper meaning and understanding. Van Laer and Elen (2016) define reflection cues as prompts that aim to activate learners' purposeful critical analysis of knowledge and experience, in order to achieve deeper meaning and understanding. This definition occurs via three major questions (Farrall, 2007; Mann, Gordon, \& MacLeod, 2009): 
- 6.1. Reflection-before-action. Does the reflection-for-action approach apply (Farrall, 2007)? This type is different from the other two types since it is proactive in nature. For example the instructor asks the learner about his or her personal expectations about an upcoming task.

- 6.2. Reflection-in-action. Does the reflection-in-action approach apply (Farrall, 2007; Schön, 1987)? This type of reflection takes place while learners are performing a task. Reflective cues are given when the learner is performing a certain task. Cues are given to let him reflect upon if he needs to alter, amend, change what he is doing and being in order to adjust to changing circumstances, to get back into balance, to attend accurately, etc.? Learners must check with themselves that they are on the right track: if I am not on the right track, is there a better way? For example an instructor asks learners to review the actions they are undertaking.

- 6.3. Reflection-on-action. Does the reflection-on-action approach apply (Farrall, 2007)? Munby and Russell (1992) describe it succinctly as the "systematic and deliberate thinking back over one's actions". Another definition which involves thinking back on what teachers have done to discover how knowing-in-action might have contributed to unexpected action (Hatton \& Smith, 1995). For example an instructor asks the learner about his or her previous experiences regarding a task that is just finished.

\section{Calibration cues}

Calibration is defined as the learners' perceptions of performance compared to the actual performance and perceived use of study tactics and actual use of study tactics (Bol \& Garner, 2011). Calibration concerns on the one hand the deviation of a learner's judgment from fact, introducing notions of bias and accuracy and on the other hand metric issues regarding the validity of cues' contributions to judgments and the grain size of cues (Azevedo \& Hadwin, 2005). Van Laer and Elen (2016) define calibration cues as triggers for learners to test their perceptions of performance against their actual performance and their perceived use of study tactics against their actual use of study tactics. While identifying calibration cues we focus on five major questions (Nietfeld, Cao, \& Osborne, 2006; Thiede \& Dunlosky, 1994):

- 7.1. Cues for delayed metacognitive monitoring. Is a strategy applied to guide learners to delay metacognitive monitoring? (Thiede \& Dunlosky, 1994)This strategy is based on a phenomenon labelled 'the delayed judgement of learning effect' that shows improved judgments after a learning delay similar to improved performance associated with distributed sessions over time. For example, learners might be first asked to highlight a text and at a later time evaluate the highlighted content in terms of how well it is understood, how easily is can be retrieved, and how it relates to the learning objective. They are asked to evaluate previously made judgements.

- 7.2. Forms for summarizing. Is a strategy applied for the provision of forms that guide students to summarize content? Summarizing information improved calibration accuracy. It is suggests that the summaries were more effective when forms and guidelines were provided (Wood, Woloshyn, \& Willoughby, 1995). For example an instructor gives the learners the task to summarize a specific content component and to review it using a correction key.

- 7.3. Timed alerts. Are timed alerts given that guide students to summarize content? Thiede, Anderson, and Therriault (2003) state that summarizing information after a delay improved calibration accuracy. 
- 7.4. Review of the 'right' information. Is a strategy applied for helping learners review the "right" information? (Bol \& Garner, 2011) Learners have a tendency to select "almost learned" or more interesting content for restudy. If students were to rate test items on judgement of learning and interest they could be provided with feedback indicating that selection of content for restudy based on interest and minimal challenge may not be the best choices. For example an instructor advises the learners to select exercises that are challenging for them.

- 7.5. Effective practice tests. Is a strategy applied for effective practice tests that provide students with records of their performance on past tests as well as items (or tasks) on those tests? (Bol \& Garner, 2011) Learners should be aware of the change in behaviour they should make. By informing them of the mistakes they already made they might direct further attempts. For example an instructor gives the results of the previous test as a guideline for the completion of the next test. 


\section{Appendix 3: Overview of blended learning environments described}

Overview

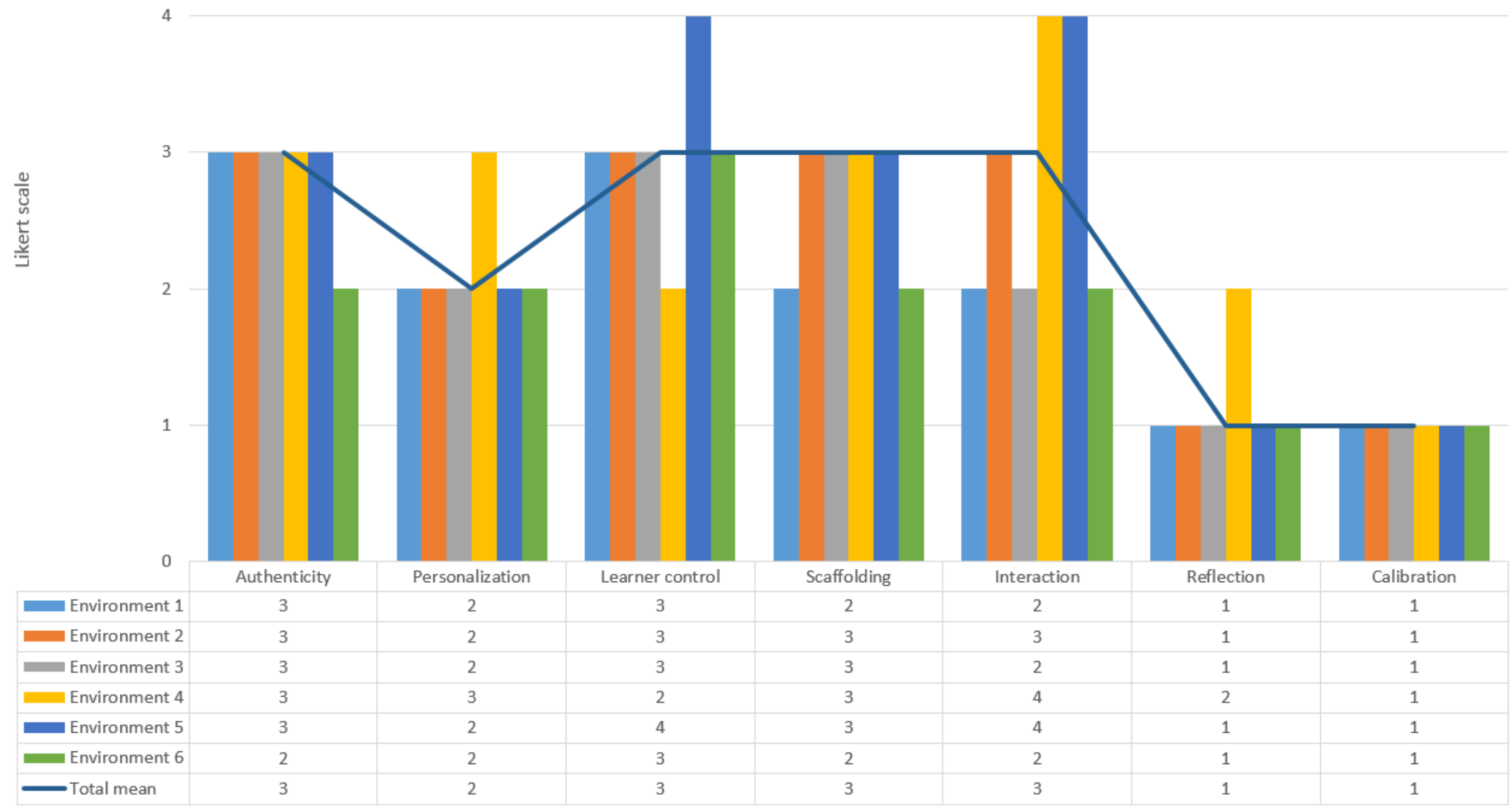




\section{Appendix 4: Variables traced per school}

School A

Content

Content

related

information

Tasks and assignments

Scores and results
1. Course module viewed $(p<.05)$

2. Course searched

3. Course viewed $(p<.05)$

4. List of modules viewed

5. User logged in in course

6. Content posted $(p<.05)$

7. Discussion made $(p<.05)$

8. Discussion viewed $(p<.05)$

9. Enrolled on discussion $(p<.05)$

10. Message made $(p<.05)$

11. Message modified $(p<.05)$

12. Note created

13. Note removed

14. Post made

15. Subscription made on discussion

16. Subscription removed
17. Assignment made $(p<.05)$
18. Assignment saved $(p<.05)$
19. Assignment sent $(p<.05)$
20. File uploaded $(p<.05)$
21. Submissions made
22. Test attempt viewed $(p<.05)$
23. Test made $(p<.05)$
24. Test started $(p<.05)$
25. Test viewed
26. There is an uploaded file
27. User preserved submission
Tasks and
assignments

28. Score overview viewed

29. Status of assignment viewed $(p<.05)$

30. Submission form consulted $(p<.05)$

31. Summary test attempts viewed $(p<.05)$

32. Test attempt reviewed $(p<.05)$

33. Test checked

34. User score $(p<.05)$
School B

Content

1. Course module viewed $(p<.05)$

2. Course viewed $(p<.05)$

3. Feedback viewed

4. List of modules viewed

5. SCORM started $(p<.05)$

6. User logged in in course

Content

7. Discussion created $(p<.05)$

related

8. Discussion viewed $(p<.05)$

information

9. Note created

10. Note removed

11. Post made

12. Subscription made on discussion

13. Subscription removed

14. User profile viewed

15. Assignment made $(p<.05)$

16. Assignment saved $(p<.05)$

17. Assignment sent $(p<.05)$

18. File uploaded $(p<.05)$

19. Test viewed

20. There is an uploaded file

21. User preserved submission

Scores and

22. Score report viewed $(p<.05)$

results

23. Status assignment viewed $(p<.05)$

24. Submission form viewed $(p<.05)$

25. Test checked

26. User score $(p<.05)$ 

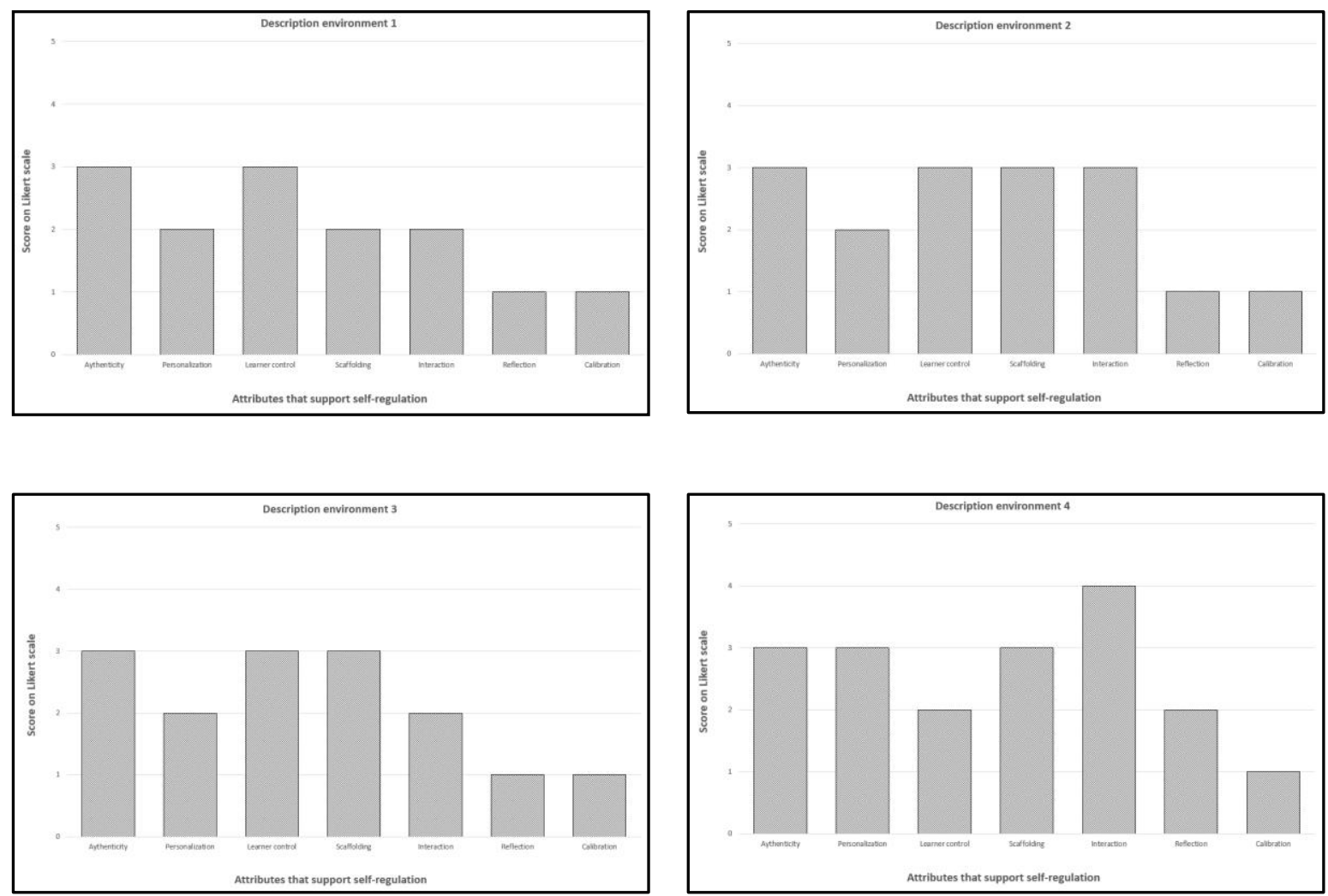

Figure 1. Amount of attributes identified for each environment of school A.
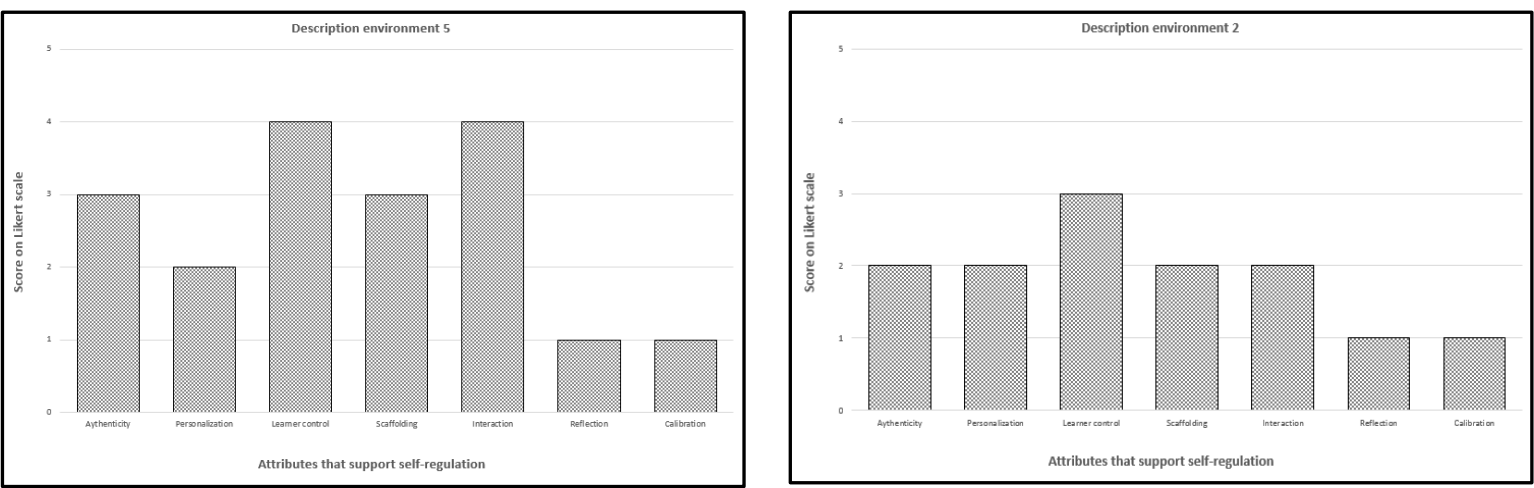

Figure 2. Amount of attributes identified for each environment of School B. 


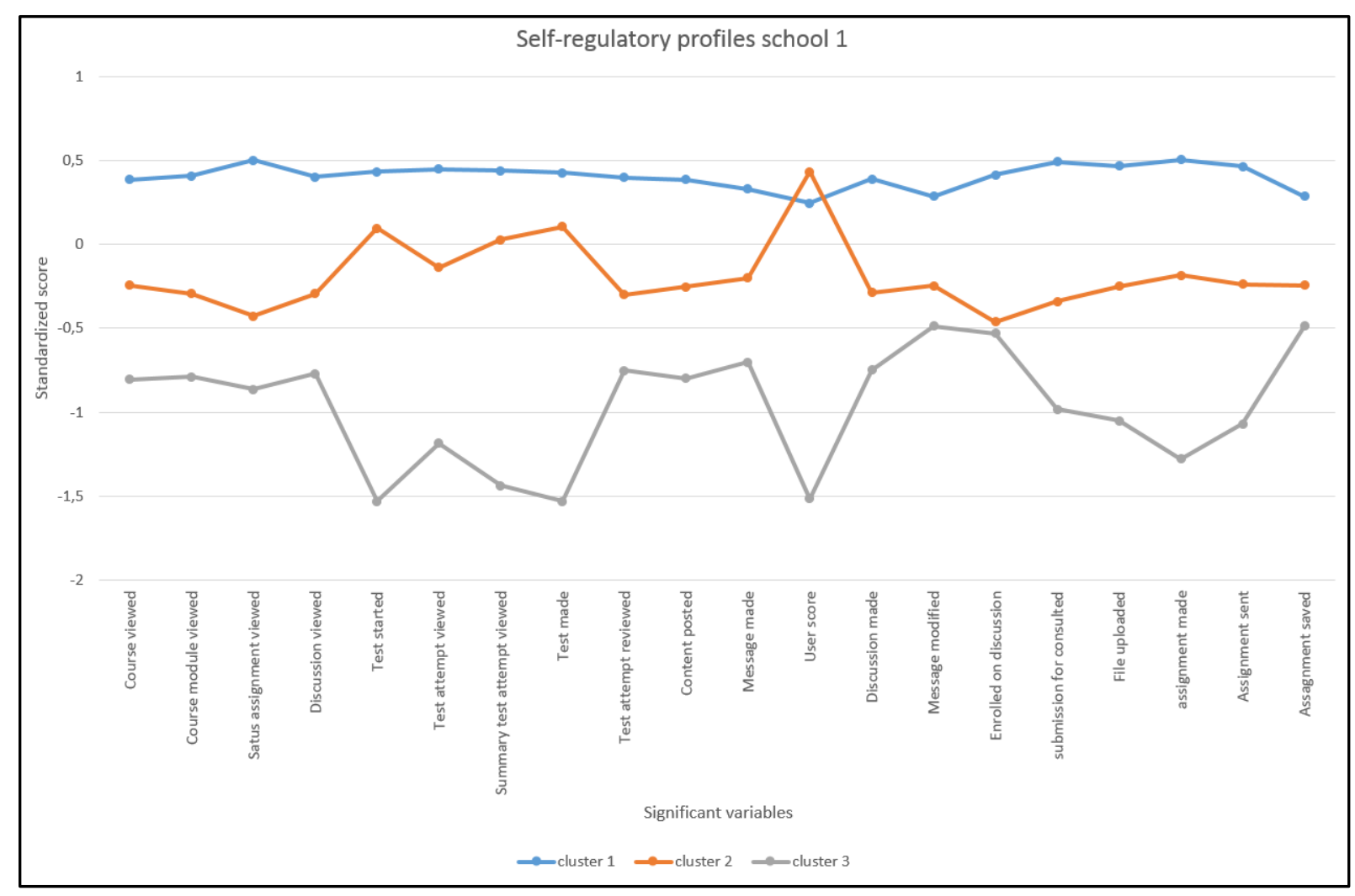

Figure 3. Three clusters of School A based on the significant different variables plotted on the standardized mean scores.

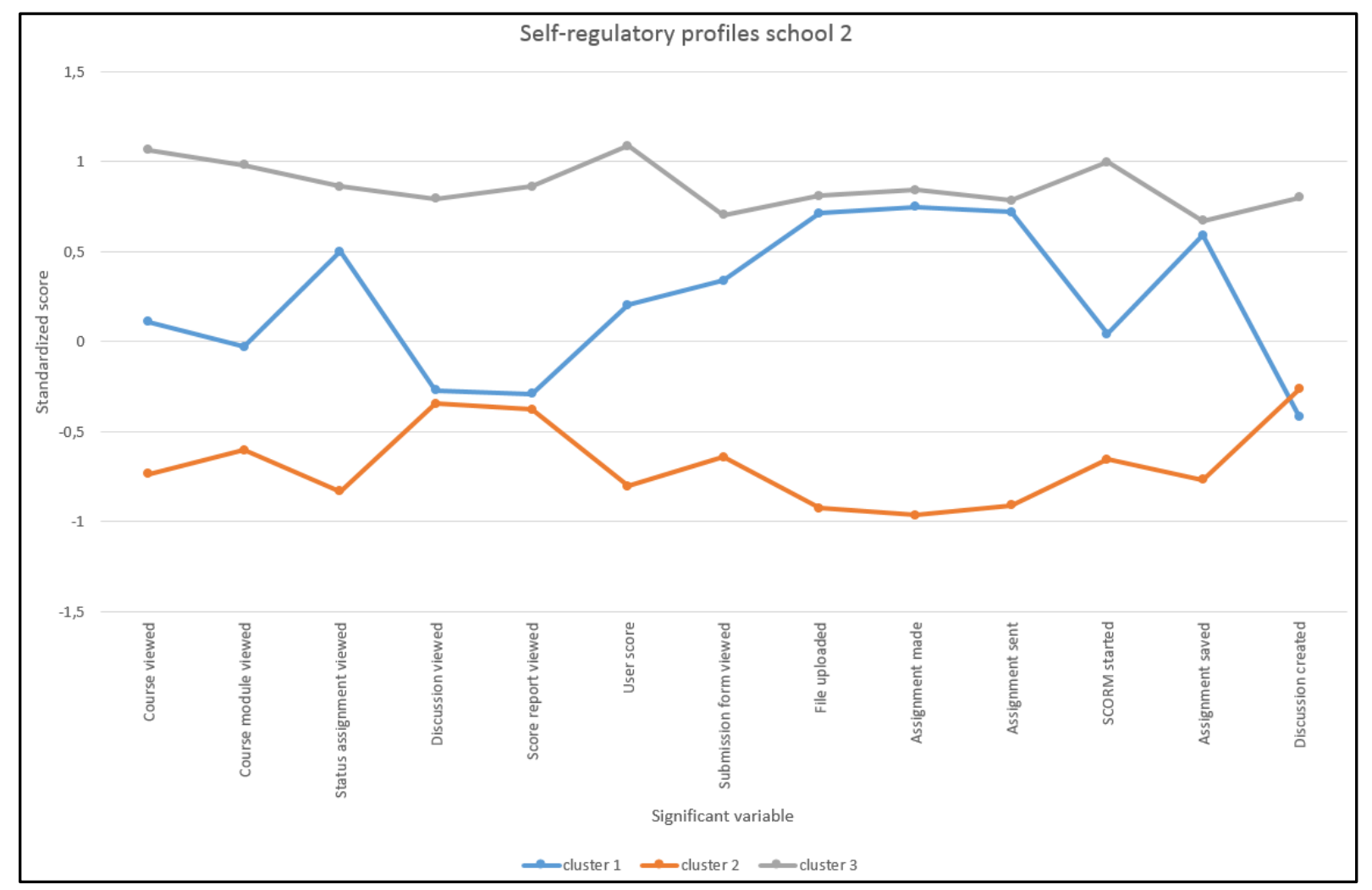

Figure 4. Three clusters of School B based on the significant different variables plotted on the standardized mean scores. 


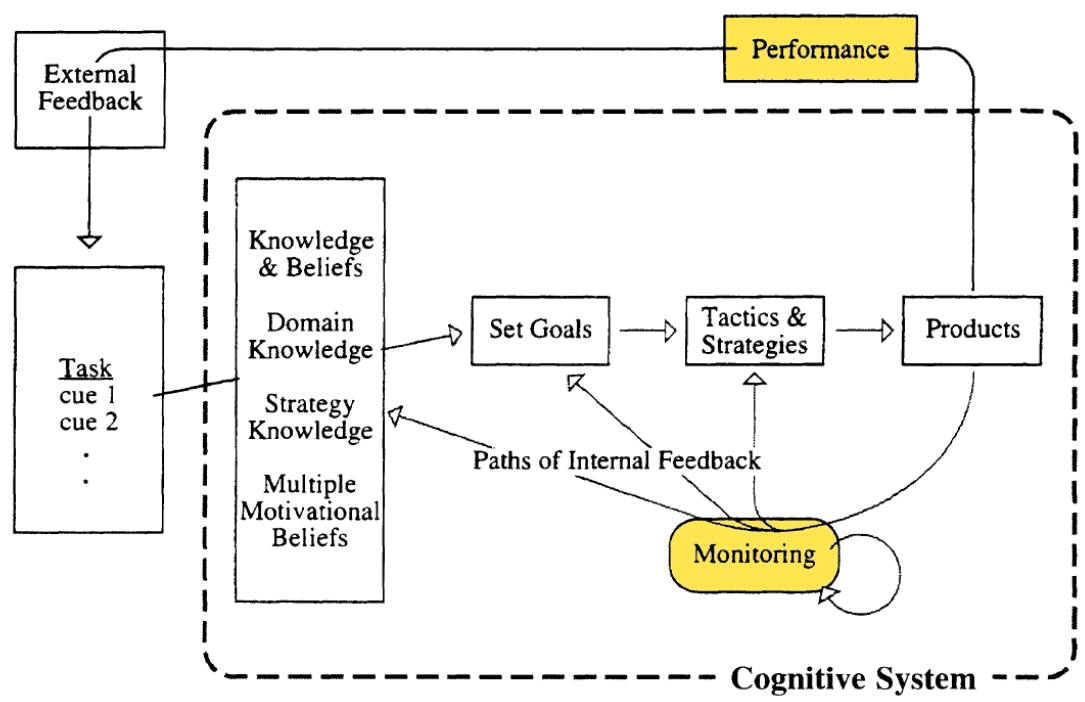

Figure 5. Butler and Winne (1995) model of self-regulation. From: Butler, D. L., \& Winne, P. H. (1995). Feedback and self-regulated learning: A theoretical synthesis. Review of educational research, 65(3), 245-281. 